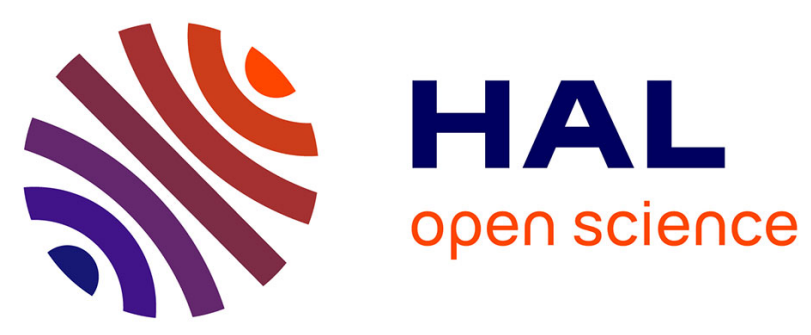

\title{
Thermo-physical characterization of Hexadecane during the solid/liquid phase change
}

Nicolò R Sgreva, Justine Noel, Christel Métivier, Philippe Marchal, Hadrien Chaynes, Mykola Isaiev, Yves Jannot

\section{- To cite this version:}

Nicolò R Sgreva, Justine Noel, Christel Métivier, Philippe Marchal, Hadrien Chaynes, et al.. Thermophysical characterization of Hexadecane during the solid/liquid phase change. Thermochimica Acta, 2022, 710, pp.179180. 10.1016/j.tca.2022.179180 . hal-03913572

\section{HAL Id: hal-03913572 \\ https://hal.science/hal-03913572}

Submitted on 27 Dec 2022

HAL is a multi-disciplinary open access archive for the deposit and dissemination of scientific research documents, whether they are published or not. The documents may come from teaching and research institutions in France or abroad, or from public or private research centers.
L'archive ouverte pluridisciplinaire HAL, est destinée au dépôt et à la diffusion de documents scientifiques de niveau recherche, publiés ou non, émanant des établissements d'enseignement et de recherche français ou étrangers, des laboratoires publics ou privés. 
1

\section{Abstract}

\title{
Thermo-Physical characterization of Hexadecane during the solid/liquid phase change
}

\author{
Nicolò R. Sgrevaa,*, Justine Noel ${ }^{\mathrm{a}}$, Christel Métivier ${ }^{\mathrm{a}, * *}$, Philippe Marchal ${ }^{\mathrm{b}}$, \\ Hadrien Chaynes ${ }^{\mathrm{a}}$, Mykola Isaiev ${ }^{\mathrm{a}}$, Yves Jannot ${ }^{\mathrm{a}}$ \\ ${ }^{a}$ Université de Lorraine, LEMTA, CNRS, 54000 Nancy, France \\ ${ }^{b}$ Université de Lorraine, LRGP, CNRS, 54000 Nancy, France
}

In this study we provide a multi-physical and multi-scale characterization of an organic Phase Change Material (PCM), i.e. hexadecane, for both its liquid and solid phase and during the phase transition. Macroscopic thermal and physical properties provided are density and viscosity in the liquid phase and thermal conductivity and heat capacity in each phase. Further macroscopic measurements were done by differential scanning calorimetry (DSC), which was used to obtain a first estimation of temperatures at which the solid/liquid phase transition occurs. DSC results present a thermal hysteresis between melting $\left(T_{m}\right)$ and solidification $\left(T_{s}\right)$ temperature. A similar hysteresis was also collected during rotational and oscillatory rheometry at the phase change, where $T_{s}$ is found to depend on the applied cooling rate. Moreover, near $T_{s}$ the forming solid structure is continuously affected by conditions imposed by the rheometer (i.e. applied shear rate or stress) and the breakage of crystals takes place even at the weak imposed stress tested (0.001 Pa). Beside the bulk behavior, the local melting and solidification were studied at microscopic scale through Raman spectroscopy. The local melting temperature is very close to what found by DSC and by rheometry. On the other hand, crystallization onset is found at higher temperatures for long waiting times, thus considerably reducing the thermal hysteresis. Finally, we highlight a key influence of interfaces on the phase transition. Variations in boundary conditions (thermal and/or kinematical conditions) are found responsible for the way hexadecane's solidification occurs.

Keywords: Phase Change Materials, Hexadecane, Solidification, Melting, Multi-scale characterization

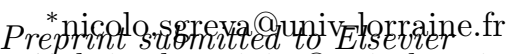

**christel.metivier@univ-lorraine.fr 


\section{Introduction}

Continuous increase in fossil energy consumption and in energy supply leads to crucial impact on the climate change. Therefore, major efforts have been made in recent years to promote a more responsible use of the extracted energy. A promising way to do so concerns the optimization of technological processes via recovery and further reuse of waste heat produced. These latter constraints require the development of efficient and low-cost thermal energy storage (TES) systems.

Among the available ways to store thermal energy, the heat energy generated/absorbed during phase transition is one of the most widely used [1,2]. Phase change materials (PCMs) which theoretically exhibit significant latent heat per unit of volume are the basic components of such thermal energy storage devices. Such materials allow to store the latent heat during the melting and release that energy during the solidification process. The main advantages of PCMs based systems lie in (i) a quasi-constant temperature at which the phase transition occurs (for mono-component PCMs or eutectics) $[2,3,4]$, and (ii) the reversibility of storage/release cycles as long as the materials do not present significant ageing effects [5] or thermal instabilities [6].

The usage of PCMs can have a strong impact also on the environmental health care. In sustainable architecture, PCMs are employed for example to maintain indoor steady temperatures near the thermal comfort for long periods [5]. This decreases the need of heating, ventilating and air conditioning systems, which account to more than half of the total energy consumed in buildings [7], and therefore decreases the energy consumption and the emission of greenhouse gas, playing an important role in the decarbonization. Similarly, PCMs are involved in a large range of smart engineering processes, e.g. in the transport of food or pharmaceuticals such as vaccines $[8,9]$, in electronic systems [10], in smart textiles [11], etc. PCMs are also a key topic in geophysics where a clear knowledge of how thermal and mechanical properties of partial melted rocks vary near phase transitions is essential to properly model crustal magmatic systems [12].

Commercially available PCMs differ from each other in physical-chemical characteristics, thermal properties and phase transition temperatures [13, 14]. They are commonly divided in organic PCMs, inorganic PCMs and a combination of the two. Beside their usually higher latent heat and low cost, inorganic PCMs undergo corrosion, decomposition and thermal stability defi- 
ciency, making them less attractive than the organic counterpart [5]. Organic PCMs, e.g. paraffin and fatty acid, have much more stable thermo-physical properties and more suitable phase transition temperatures for a wide range of applications. However, their main drawback falls in a quite low thermal conductivity (e.g. $\lambda \sim 0.2 \mathrm{~W} \mathrm{~m}^{-1} \mathrm{~K}^{-1}$ for liquid paraffin waxes), that leads to slow charging and discharging rates $[4,5,15]$. There are several ways to improve the heat transfer, for instance: (1) by using micro-encapsulated PCMs [16, 17], (2) by triggering the phase change in convective regime [10], and (3) through the usage of composite shape-stabilized PCM systems that increase their thermal conductivity [18]. Micro-encapsulated PCMs (1) have the main advantage of increasing the surface to volume ratio of PCM, i.e. the effective surface where heat transfer occurs [19]. The PCM is stored as core of microcapsules and is coated with a polymer layer. This solution allows to avoid leakage and to reduce reactions with the external environment during phase transition. The second way (2) to enhance heat transfer consists in performing the phase change with convection. When, in the liquid PCM, the dominant heat transfer mode is convection, the melting rate increases and the melting interface moves faster [20]. The most common composites PCM systems (3) consists in inserting PCMs in a porous matrix with high thermal conductivity. A large amount of experimental and numerical studies has been carried out for different combination of PCMs with porous supports (e.g. metal or graphite foams, beads, etc.). A recent and extensive review on the topic is given by Zhang et al. [2]. Compared with the case of a pure $\mathrm{PCM}$, heat is in this case more efficiently transferred away from the heating source because of the higher thermal conduction of the porous medium [21]. Although any combination of methods (1) to (3) is possible, in some cases they can counteract each other. For instance, solid foams with high thermal conductivity can drastically delay the occurrence of natural convection in liquid phase $[22,23]$ since relative buoyancy driven forces are smaller than diffusive (dissipative) effects. As this example points out, it becomes essential to understand the physical mechanisms at stake as well as being able to quantify them. This involves a detailed knowledge of materials properties. Above this specific case, given the wide use of PCMs in engineering processes it is of utmost importance to properly determine their thermophysical properties. This concerns PCMs thermal properties (e.g. thermal expansion, thermal diffusivity, melting and solidification temperatures etc.) and physical properties (e.g. viscosity) within specific time scales (e.g. fast or long runs, transient or steady state conditions), both at the phase transi- 
tion and for each phase. These properties are not always easily measurable as they strongly depend on the methods/protocols involved [24, 25, 26]. An inaccurate estimation of their value or the way they vary close to the phase transition can lead to wide discrepancies in the description of the materials behavior. On the importance of the correct definition of PCMs properties, Arkar et al. [27] show how the thermal response of a TES system depends on the accuracy of the properties measured. The authors highlight the importance in taking into account variations of PCMs apparent heat capacity with the cooling/heating rate to which they are subjected to. These variations are critical in their models as they study the transient response of a TES system.

Beside the specific heat capacity, in problems driven by temperature variations, another crucial material property is the thermal conductivity $\lambda$. For the specific case of paraffin, if the thermal conductivity for the liquid phase alone is usually well known [e.g. 25, 28, 29], there are not many studies that report the variation of thermal conductivity between liquid phase and solid phase embracing also the phase transition region. Only recently Vélez et al. [15] reported an experimental study on thermal conductivity and diffusivity of three paraffins in both their liquid and solid phases by using the hot wire technique. They have found that the thermal conductivity is larger in the solid phase than in the liquid phase for any tested paraffins. Moreover, $\lambda$ is found nearly constant for temperatures much lower than the melting temperature, while it slowly decreases for temperature close to the melting one. The evolution of thermal conductivity with temperature is then characterized by a sharp discontinuity once the melting temperature is reached. Even though the data at the transition show a larger dispersion of $\lambda$ due to the latent heat that may have affected the temperature in the setup, Vélez et al. [15] always recorded a sudden jump in $\lambda$ values characterizing the phase change. In the same paper, they also performed DSC measurements in order to measure the heat transfer involved during the phase change. This allows in the first place to evaluate the temperature at which the solid-to-liquid and the liquid-to-solid transitions take place. For the paraffin with a least number of carbon atoms used (i.e. hexadecane), they display a thermal hysteresis between melting and solidification temperatures of about $1{ }^{\circ} \mathrm{C}$. This value of thermal hysteresis varies between different authors. For instance, for the same paraffin and always by measuring the transition temperatures with DSC but with faster temperature variations, Fang et al. [30] obtain an hysteresis of $4.6{ }^{\circ} \mathrm{C}$ whereas Moulahi et al. [31] and Chriaa et al. [32] one of 
$11.6{ }^{\circ} \mathrm{C}$. The absolute value of such hysteresis strongly depends on the experimental conditions. Moreover, the rate of cooling also plays a major role on supercooling effects $[33,34]$. Supercooling takes place during the liquidto-solid phase transition and leads to a delay in the crystallization onset, that is the material remains liquid even at temperatures smaller than the freezing temperature. Short experimental times, e.g. an increase in cooling rate, would result in an increase in the degree of supercooling, defined as the temperature difference between the melting and crystallizing temperatures, as shown by Safari et al. [33].

Thermo-physical properties have to be carefully determined with temperature variations since Boussinesq approximation is only valid in a narrow temperature range. Hence, properties such as viscosity $\eta$, density $\rho$ and coefficient of thermal expansion $\beta$ must also be measured as the temperature varies, especially in the case of coupling heat transfer and fluid flows. To our knowledge, the viscosity of paraffin has been scarcely studied close to the phase transition temperature or even across the phase transition. The rheological behavior of octadecane was studied by Delgado et al. [35] who performed rotational and oscillatory tests at different heating/cooling rates. They found that the viscosity can span over several order of magnitudes (up to six) during the phase change. From oscillatory rheological tests performed with different temperature ramps, they were able to measure variations of the complex viscosity, i.e. the viscosity derived from measured values of storage and loss moduli, during the phase transition. As for DSC, also rheological analysis shows a thermal hysteresis between melting and solidification processes that depends on the temperature ramp imposed during the experiment $[35,36]$. Similar results were obtained performing a set of intercomparative tests with different rheometers on octadecane [37] and on RT25 paraffin [38].

More precise analysis of phase transition requires the measurement of local state close to the melting/solidification temperature. Such insight can be obtained with the use of various spectroscopic approaches, which, from microscopical point of view, give access to vibrational properties of molecules inside the system. Such vibrations depend on the types of atoms, their interactions, and the distance between them; and therefore their study allows to detect structural changes with a quite good accuracy. In such way, Raman spectroscopy has been already applied for the investigation of phase transition of paraffin by Marchetti et al. [39] and Corsetti et al. [40]. Specifically, they shown that from the temperature-dependent Raman spectra some well recognizable patterns can be used to decompose the contributions of the 
liquid and solid phase. In this way, the phase transition can be detected through convectional analysis of spectra with respect to wavenumbers shifts and intensity ratio between specific peaks and by using principal component analysis (PCA). They found that by combining these analyses, the temperature at which the paraffin starts to change phase is well resolved by spectra changes.

PCMs characterization is fundamental. The literature is clearly abundant on this topic, however results are scattered, mostly partial and experimental conditions/protocols are often insufficiently detailed. In the present paper, we propose a fully characterization of an organic PCM, i.e. hexadecane. To do so, different techniques were employed and different protocols were tested, leading to the determination of the main macroscopic thermo-physical properties both for the two phases and during the phase change. In parallel, structural information are also provided by using Raman spectra analysis. They allow us to investigate accurately the crystallization and the melting processes and to provide local measurements of transition temperatures.

Hexadecane is a straight-chain alkane hydrocarbon with 16 carbon atoms and chemical formula $\mathrm{CH}_{3}\left(\mathrm{CH}_{2}\right)_{14} \mathrm{CH}_{3}$. Two properties make it attractive for experiments dealing with PCMs: its high latent heat and the fact that the temperature at which the phase change takes place is near the room temperature [15].

Although widely used, literature on hexadecane lacks of experimental studies regarding both a proper investigation of its thermal properties and rheological behavior near the phase transition. By covering the phase transition region we provide, in section 2 , novel values of thermal conductivity for both solid and liquid phase. Moreover, we discuss the impact that experimental conditions may have on the proper measurement of transition temperatures since the thermal hysteresis between melting and solidification processes is found to be dependent on the heating/cooling rate. Afterward we provide in section 3 the first experimental rheological analysis for hexadecane during the phase change. As pointed out in [35], there are surprisingly only few experimental studies dealing with the rheological behavior of $n$ alkane, none of which employ hexadecane. Similarly to Delgado et al. [35], we performed rotational and oscillatory tests with varying heating/cooling rates where the role played by either the shear rate or the stress is highlighted. Carrying out oscillatory tests in addition to standard rotational tests is crucial to provide rheological properties of PCMs when a solid phase develops. This is because, for small solicitations, oscillatory tests modify the 
sample's structure as little as possible and let the crystals grow. In the same section we propose further original rheological tests during the phase change where we followed the time evolution of the bulk deformation and viscoelastic moduli at constant temperature. The structural investigation of the PCM is provided in section 4 by exploring locally the phase change by Raman spectroscopy. A systematic analysis of temperature dependent patterns in Raman spectra of hexadecane is then given by showing the main differences recognizable during both the melting and the crystallization of the sample. Discussion and conclusions end the paper in the last section 5 .

\section{Hexadecane physical and thermal properties at the macroscopic scale}

The samples of hexadecane were supplied by Sigma-Aldrich (CAS number 544-76-3). They were labeled as $99 \%$ pure and with a phase change temperature of $T=18{ }^{\circ} \mathrm{C}$. They were used as received, i.e. without any further purification or removing impurities.

\subsection{Density and thermal expansion}

The temperature dependence of density was measured for hexadecane (sample volume $\sim 1 \mathrm{~mL}$ ) at ambient atmospheric pressure with a DMA $5000 \mathrm{M}$ Anton-Paar densimeter which allows measurements only for liquid materials. For hexadecane, data were collected every $1{ }^{\circ} \mathrm{C}$ from temperature $T=40.0^{\circ} \mathrm{C}$ to $T=16.0{ }^{\circ} \mathrm{C}$. For the latter temperature the sample was still liquid, we attribute this to undercooling effects. The waiting time for measurement stabilization was about five minutes. Without phase change, this stabilization time was sufficient given the small volume of fluid employed, and results were reproducible with a maximum variation of $5 \times 10^{-6} \mathrm{~kg} \mathrm{~m}^{-3}$. The resulting dependence of density on temperature is shown in Fig. 1 where it is also linearly fitted by the equation

$$
\rho(T)=-0.6854 T+787.2 \mathrm{~kg} \mathrm{~m}^{-3},
$$

with $T$ in ${ }^{\circ} \mathrm{C}$. Equation (1) is obtained from our experimental data only and, by considering other measurements provided in [41] and [42], it is also valid for a wider range of temperature (Fig. 1).

The coefficient of volumetric thermal expansion is linked to the density through $\beta(T)=-\rho^{-1}(\partial \rho / \partial T)$. From our density measurements within the 


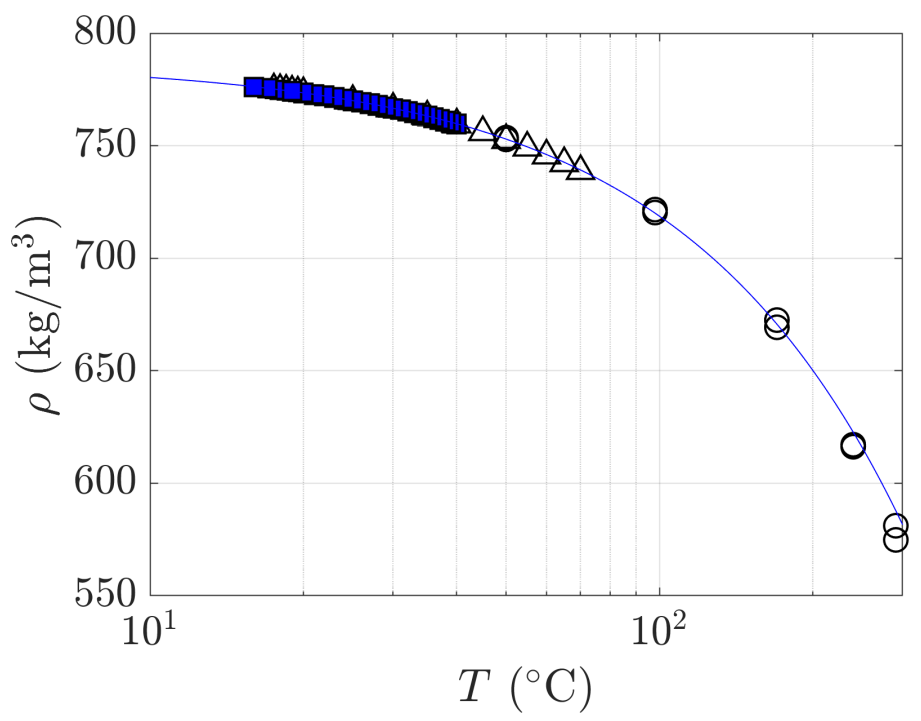

Figure 1: Density as function of temperature in log-scale. Blue squared symbols represent our measurements. The blue line is the fit of our data alone, the fit equation is $\rho(T)=$ $-0.6854 T+787.2 \mathrm{~kg} \mathrm{~m}^{-3}\left(\mathrm{R}^{2}=0.9996\right)$. Black triangles are values from Outcalt et al. [41] and circles are from Matthews et al. [42].

temperature range of $16.0{ }^{\circ} \mathrm{C}$ and $40.0{ }^{\circ} \mathrm{C}$, liquid hexadecane has a positive coefficient of thermal expansion, leading to an increase in the volume as temperature rises. At temperature $T=20.0{ }^{\circ} \mathrm{C}$, it results $\beta=8.861 \times$ $10^{-4}{ }^{\circ} \mathrm{C}^{-1}$.

\subsection{Thermal conductivity}

The thermal conductivity $\lambda$ of hexadecane for both liquid and solid phase was measured using the hot tube steady state method (see [43], p. 106-107). Below we briefly report the principles on which this method is based and the experimental set-up. The set-up consists in two $200 \mathrm{~mm}$-long co-axis cylinders with the outer one in contact with a water flow maintained at controlled temperature (Fig. 2). A volume of $\sim 18 \mathrm{~mL}$ of PCM filled all the gap between these two cylinders. The inner cylinder is $0.22 \mathrm{~mm}$ thick and it is made of stainless steel, with an outer radius, corresponding to 'cylinderPCM' interface, of $r_{1}=2.76 \mathrm{~mm}$. The outer cylinder is $1 \mathrm{~mm}$ thick and it is made of copper with the inner surface in contact with the PCM sample at $r_{2}=6.00 \mathrm{~mm}$. The inner cylinder was heated up by Joule effect via a controlled electric intensity. 


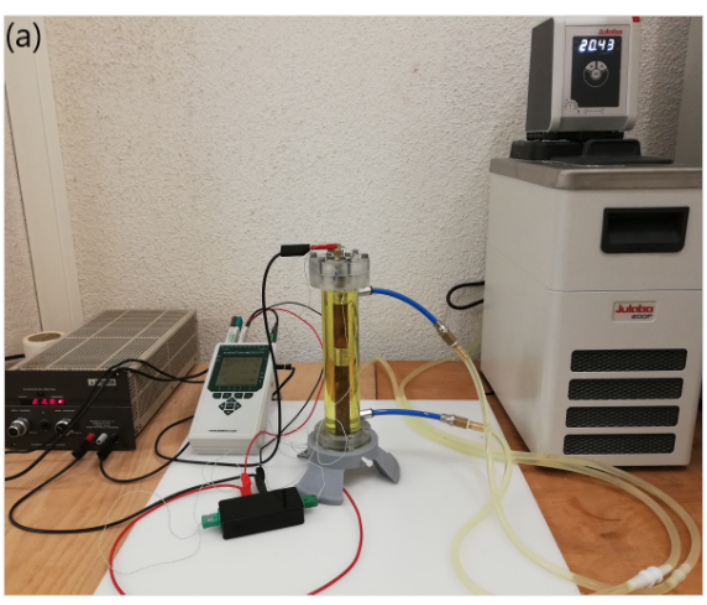

(b)

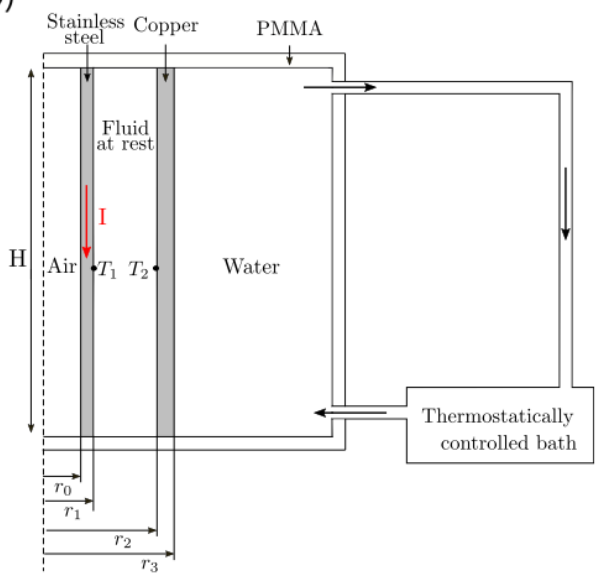

Figure 2: Hot tube device used to measure the thermal conductivity. (a) Photo of the entire setup where (I) indicates the hot tube device; (II) the current generator; (III) the temperature data logger (Almemo 2890-9, Ahlborn); (IV) an homemade device to measure the difference in voltage between the two thermocouples; and $(\mathrm{V})$ the thermal Bath (Julabo eco). (b) Schematic representation of the hot tube device alone. The device consists of two co-axial cylinders of height $H=200 \mathrm{~mm}$. The inner stainless-steel-cylinder has an internal radius $r_{0}=2.54 \mathrm{~mm}$ and an external radius $r_{1}=2.76 \mathrm{~mm}$. The outer coopercylinder has an internal radius $r_{2}=6.00 \mathrm{~mm}$ and an external radius $r_{3}=7.00 \mathrm{~mm}$ and it is in contact with a water flow. 
Temperatures were measured by two K-type thermocouples positioned at the interfaces between cylinders and PCM sample; i.e. the first one (measuring $T_{1}$ ) was positioned at $r=r_{1}$ and the second one (measuring $T_{2}$ ) at $r=r_{2}$, both at half of the the cylinders height in order to avoid any up-down wall effects.

Within this framework, the thermal conductivity can be calculated from the following expression:

$$
\lambda=\frac{\rho_{e} I^{2} \ln \left(r_{2} / r_{1}\right)}{2 \pi^{2}\left(r_{1}^{2}-r_{0}^{2}\right)\left(T_{1}-T_{2}\right)},
$$

where $\rho_{e}$ is the specific electrical resistivity of stainless steel and $I$ the electrical intensity. Within our experiments, the temperature difference $T_{1}-T_{2}$ varies from $3{ }^{\circ} \mathrm{C}$ to $10{ }^{\circ} \mathrm{C}$. Figure 3 shows how the thermal conductivity of hexadecane evolves as a function of the mean temperature between the two cylinders, i.e. $\bar{T}=\left(T_{1}+T_{2}\right) / 2$. Measurements were carried out within a range of $\bar{T}$ between 6 and $37^{\circ} \mathrm{C}$. Thermal conductivity data and corresponding temperatures measured by thermocouples are summarized in supplementary material.

The first measurement of $\lambda$ was carried out in the solid phase at $\bar{T}=6.3^{\circ} \mathrm{C}$. The temperature was much smaller than the melting temperature suggested by the manufacturer in order to ensure that the entire sample volume was solid. Each step in solid and liquid phase lasted 20 minutes, long enough to guarantee that the difference in temperature between the two thermocouples reached steady state. Steps were longer (around two hours) during the phase transition.

In the solid phase, results are displayed in Fig. 3 (blue symbols). The thermal conductivity is found mainly constant with an averaged value of $\lambda=0.341 \mathrm{~W} \mathrm{~m}^{-1} \mathrm{~K}^{-1}$. Measurements were carried out about 2 or 3 times in order to verify the reproducibility of the results. It is all the more important to repeat runs since the volume decreases during the liquid-to-solid transition. In the case of hexadecane the volume shrinkage is moderate, preventing then any thermal resistance through the PCM layer and at the interfaces between PCM and tube - at least at half the height of the setup. Finally, a good agreement in the thermal conductivity of the solid phase is obtained with the value provided by Vélez et al. [15] which used another method, i.e. the transient hot wire method.

We proceeded afterward toward the melting of the sample by increasing the temperature through different steps. In our experiments, the thermal 
conductivity varies strongly in the $\bar{T}$ range of $15-20{ }^{\circ} \mathrm{C}$, i.e. close to the melting temperature $T_{m}$. Results in this second temperature range should correspond to a case where both a liquid substrate (near the heat source) and a solid one (far from the heat source) coexist inside the PCM layer (green symbols in Fig. 3).

When both $T_{1}$ and $T_{2}$ are above $T_{m}$, the resulting thermal conductivity corresponds to the one of the liquid phase (red symbols in Fig. 3). A third and quasi constant value of $\lambda$ is obtained $\left(\lambda=0.150 \mathrm{~W} \mathrm{~m}^{-1} \mathrm{~K}^{-1}\right)$ in the $\bar{T}$ range between $20^{\circ} \mathrm{C}$ and $37^{\circ} \mathrm{C}$.

Both values of $\lambda$ in solid and liquid phases are in good agreement with values given by Vélez et al. [15]. The deviations between our values of $\lambda$ and those of Vélez et al. are $6 \%$ and less than $1 \%$ in liquid and solid phase, respectively. However, our measurements are quite different to those proposed by Holmen et al. [44]. In this latter work, authors followed the freezing or melting front velocity in a layer of PCM presenting two superimposed phases. In this configuration, they proposed theoretical expressions for thermal conductivity of both phases by considering a thermal gradient only in the appearing phase. In our opinion, this assumption is quite difficult to reach experimentally. Beyond this aspect, their theoretical expressions for $\lambda$ highlight a strong dependency on other main parameters (e.g. melting point, interface evolution with time) whose measurements are not trivial and can lead to relative large errors. In particular, the melting point can vary with experimental conditions. Holmen et al. reported a total error in measuring $\lambda$ of about $18 \%$ for both liquid and solid phase. These sources of inaccuracy can explain the differences obtained between their results and ours and those of Vélez et al. . Deviations between our values of thermal conductivity $\lambda$ and those proposed by Holmen et al. [44] are indeed about $15 \%$ and $33 \%$ in solid and liquid phase, respectively.

As a remark, we mention that the temperature that triggers the solid-toliquid transition as well as the one at which the sample freezes entirely are badly resolved with our hot tube setup since it does not allow any optical access. Furthermore, the thermal conductivity is obtained via a temperature variation across the PCM layer. For this reason, we would expect a PCM layer composed of a liquid part and a solid part around the phase change temperature. Methods presented in the following sections are more relevant for this purpose. 


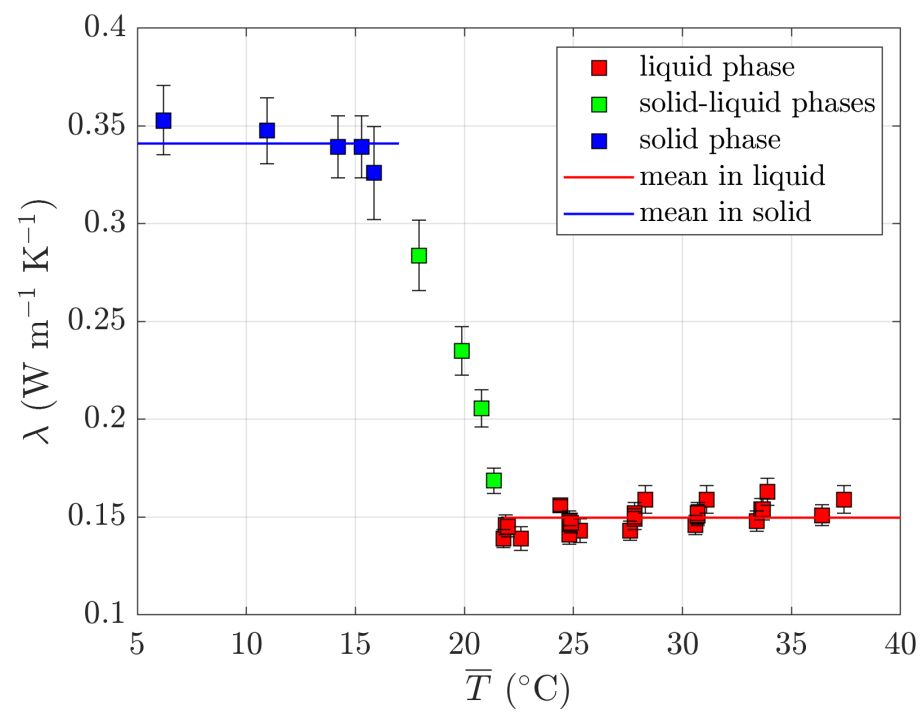

Figure 3: Thermal conductivity $\lambda$ of hexadecane as a function of temperature. $\bar{T}$ is the mean temperature between the inner and outer cylinders.

\subsection{Melting and solidification temperatures, latent heat and specific heat ca- pacity}

Differential scanning calorimetry (DSC) is a common thermal analysis technique employed to measure heat transfer involved in a small volume of material subjected to temperature variations. It allows to determine the melting and solidification temperatures, $T_{m}$ and $T_{s}$ respectively, as well as the latent heat $\Delta H_{m}$ and $\Delta H_{s}$ associated with melting and solidification phase transitions. Furthermore, it is useful also for measuring the specific heat capacity $c_{P}$ at atmospheric pressure in the solid and liquid phases. For this purpose, we used a SETERAM $\mu$ DSC3 evo calorimeter in order to characterize hexadecane within a temperature range of $10-37{ }^{\circ} \mathrm{C}$. A sample mass of $\sim 200 \mathrm{mg}$ was placed within a small crucible, the latter with a surface of average roughness of $R_{a}=0.16 \mu \mathrm{m}$ (measured with a Taylor Hobson Surtronic S116 surface roughness tester). For DSC measurements, we adopted two different protocols, one to better resolve the phase transition temperatures, and another one to estimate the heat capacity.

In the first case, the heat flux was recorded as a function of time to obtain the melting and solidification temperatures with temperature increments of about $0.5^{\circ} \mathrm{C}$ for both melting and freezing processes. Each increment lasted 
$\sim 2$ hours in order to ensure that the heat flux had vanishes, the following increment was then reached with a rate of $0.2{ }^{\circ} \mathrm{C} / \mathrm{min}$. Figure 4 shows the measured heat flux (in blue) for the different temperature increments (in red) both during temperature rise (Fig. 4a) and drop (Fig. 4b).

From Fig. 4a, the melting temperature of hexadecane is found between 17.2 and $17.7{ }^{\circ} \mathrm{C}$. This interval of $T_{m}$ includes values of melting temperature reported in other studies, most of which report temperatures that are within $18.0^{\circ} \mathrm{C} \pm 1.7 \%$ (for instance $T_{m}=18.1{ }^{\circ} \mathrm{C}$ in [45], $17.75{ }^{\circ} \mathrm{C}$ in [15], $18.3^{\circ} \mathrm{C}$ in [46] and $18.0{ }^{\circ} \mathrm{C}$ in [47]). Despite this good agreement of $T_{m}$, the solidification temperature is not well defined in these articles, and only few studies explicitly report it. From Fig. 4b, we evaluate the bulk solidification temperature of hexadecane between 15.0 and $15.5^{\circ} \mathrm{C}$, leading to an apparent thermal hysteresis of about $2{ }^{\circ} \mathrm{C}$ between the melting and the solidification of the sample. Our result of $T_{s}$ deviates of about $8-10 \%$ from others DSC measurements with $2{ }^{\circ} \mathrm{C} / \mathrm{min}[15]$ and $10^{\circ} \mathrm{C} / \mathrm{min}$ [31] cooling rates. A possible reason of such a large discrepancy can be either found in their higher solidification rates or their small amount of sample used during the DSC scans (less than $10 \mathrm{mg}$ in [15] and [31]).

Heat capacity and latent heat were measured within the temperature range of 11.2 and $37.5^{\circ} \mathrm{C}$. Temperature increments were in this case of about $2{ }^{\circ} \mathrm{C}$, and they were obtained with a cooling/heating rate of $0.2{ }^{\circ} \mathrm{C} / \mathrm{min}$. The apparent heat capacity is displayed in Fig. 5. Within this temperature range, we obtain a constant value of heat capacity in liquid phase, i.e. $c_{P}=2.24$ $\mathrm{kJ} \mathrm{kg}^{-1} \mathrm{~K}^{-1}$. In solid phase the heat capacity increases with temperature and we do not obtain a constant value within our experimental conditions. This was also observed in other works, e.g. [15] and [48]. In addition, in Fig. 5 the phase change is clearly observed since heat flux (or apparent heat capacity) varies strongly at the transition. We obtain a latent heat of melting $\Delta H_{m}=232.55 \mathrm{~kJ} \mathrm{~kg}^{-1}$ and a latent heat of solidification $\Delta H_{s}=235.95$ $\mathrm{kJ} \mathrm{kg}^{-1}$.

\section{Rheological behavior}

We performed rheological analysis on both liquid hexadecane and during the liquid-to-solid transition. A stress-controlled AR-G2 rheometer (TA Instruments) was used in rotational and oscillatory modes.

For fully liquid hexadecane we used both cone-plate and plate-plate geometries to obtain viscosity. Given the low viscosity of the material in liquid 

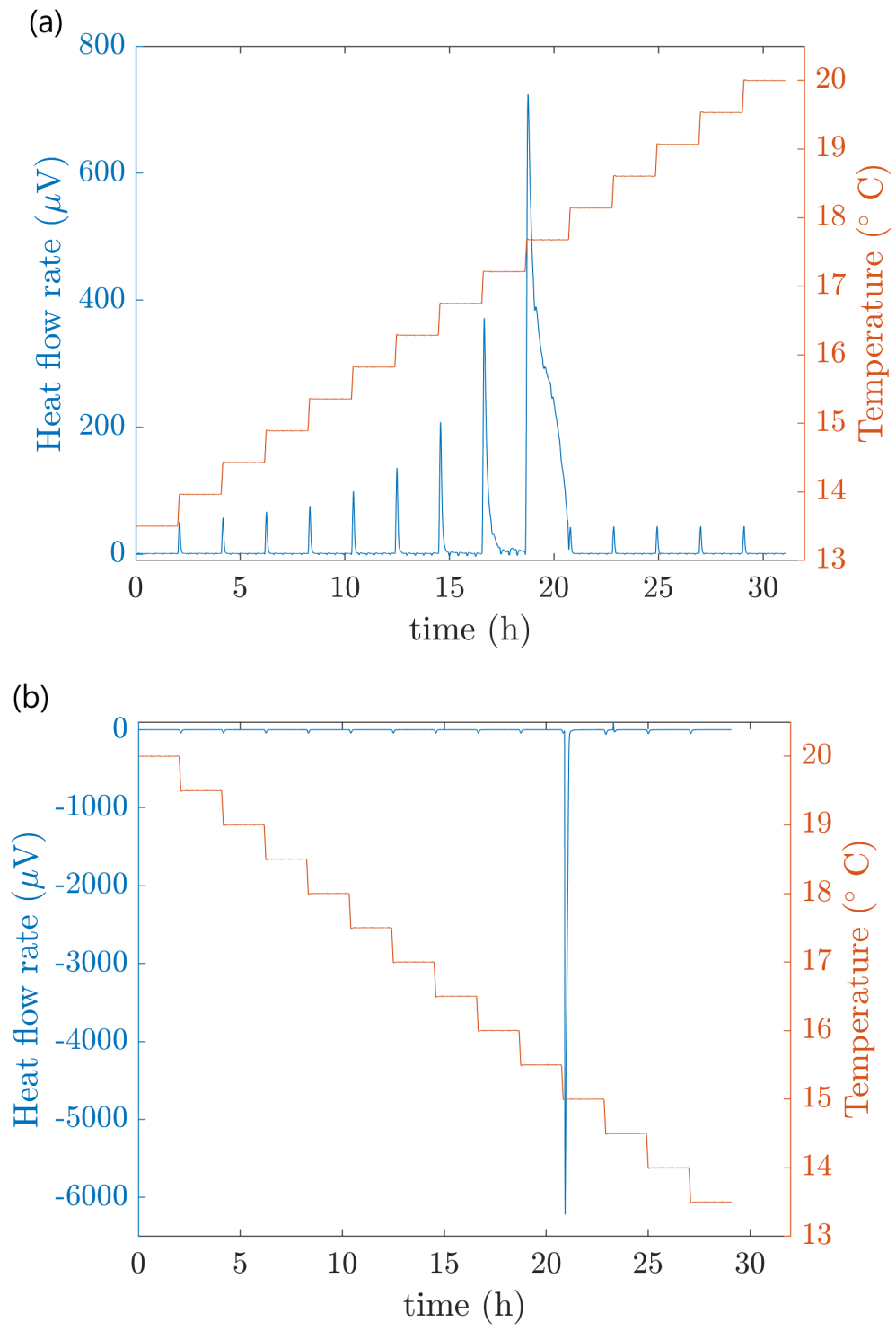

Figure 4: Heat flow rate measured from the DSC (in blue) and imposed temperature steps (in red) as a function of time. (a) Melting of hexadecane. (b) Solidification of hexadecane. 


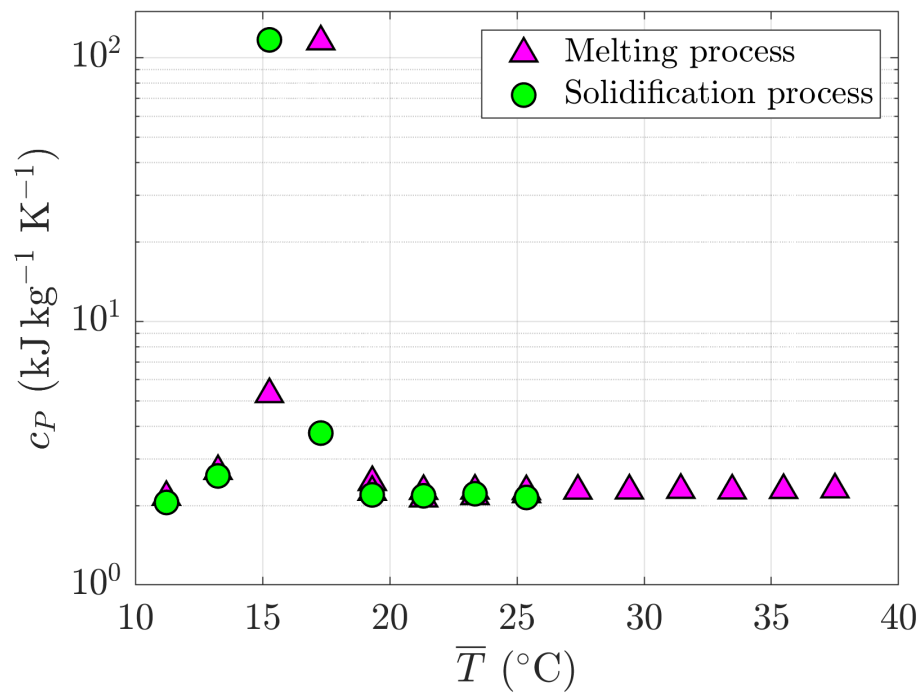

Figure 5: Apparent specific heat capacity as a function of the mean temperature of each temperature step, for both melting and solidification processes.

phase we used a large diameter $(60 \mathrm{~mm})$ for both plate and cone in order to increase the accuracy of measurements. More specifically, in cone-plate we used a $60 \mathrm{~mm}$ wide plate with a cone angle of $2^{\circ}$ and a standard gap of $70 \mu \mathrm{m}$. Both geometries lead to same results. Cone-plate geometry was used only to investigate viscosity of hexadecane in the liquid phase. At the phase change, when a solid structure develops and crystals grow, the small gap imposed by the cone-plate geometry limits the measurements (the size of solid components should not exceed the $10 \%$ of the gap to guarantee representative measures). For this reason, during the phase transition it is more appropriate to choose and use a plate-plate geometry in which the gap between plates can be adapted. For plate-plate geometry we used plates of diameter of 32, 40 and $60 \mathrm{~mm}$ and gaps of 1000 and $1200 \mu \mathrm{m}$. These gaps were found as the best compromise between ensuring isothermal conditions (i.e. low temperature differences through the sample) and guarantee an adequate distance between plates. Gaps of 500 and $2000 \mu \mathrm{m}$ were also tested. Both of them did not provide suitable results: in the first case the gap was too small compared with the size of the crystal structure, while in the second case we always observe a temperature gradient through the PCM layer.

Temperature was controlled by a Peltier plate which was covered by the 
fluid sample, the volume of which depends on the gap between the plates.

\subsection{Liquid phase}

Hexadecane's rheological properties were first determined in the liquid phase at different temperature values. We found liquid hexadecane being Newtonian with a temperature-dependent viscosity $(\eta)$. The latter was investigated in more details from temperatures close to the transition to $40{ }^{\circ} \mathrm{C}$ (Fig. 6). Within this interval of temperatures, viscosity of hexadecane exponentially decreases with increasing temperature following an exponentialtype dependency that writes

$$
\eta(T)=a e^{b\left(T-T_{0}\right)},
$$

with $a=3.3 \times 10^{-3} \mathrm{~Pa} \mathrm{~s}^{-1}, b=-1.9 \times 10^{-2}{ }^{\circ} \mathrm{C}^{-1}$ and $T_{0}=20.0^{\circ} \mathrm{C}$, as represented by the continuous line in Fig. $6 \mathrm{~b}$.

\subsection{Phase transition}

The phase transition was first analyzed following the evolution of hexadecane rheological properties during different temperature ramps (in both rotational and oscillatory modes). This procedure allows to investigate variations in viscosity (rotational mode) and in viscoelastic moduli (oscillatory mode) when crystallization starts and a solid structure develops.

Afterwards, we report the analysis of results obtained performing time sweep tests at steady temperature.

\subsubsection{Temperature ramps}

We first carried out rotational tests at fixed value of shear rate $\dot{\gamma}$ during which the sample was subjected to a temperature ramp $(1.0,0.5$ or 0.2 ${ }^{\circ} \mathrm{C} / \mathrm{min}$ ) from an initial value of $20{ }^{\circ} \mathrm{C}$ down to temperatures below the solidification one $\left(T_{s}\right)$.

We used a plate of $32 \mathrm{~mm}$ in diameter with a constant gap (equal to $1000 \mu \mathrm{m}$ ), while different shear rates were tested, i.e. $\dot{\gamma}=0.1,1,10$ and 50 $\mathrm{s}^{-1}$. Figure 7 shows the evolution of viscosity as a function of temperature. One can observe how viscosity increases of about 4 orders of magnitude from liquid to solid phase, with a transition temperature close to the one obtained by DSC which, however, depends on the chosen temperature ramp. As expected, for large temperature ramp (i.e. $1.0^{\circ} \mathrm{C} / \mathrm{min}$ ), we always observe solidification temperatures lower than what obtained with the smallest ramp 


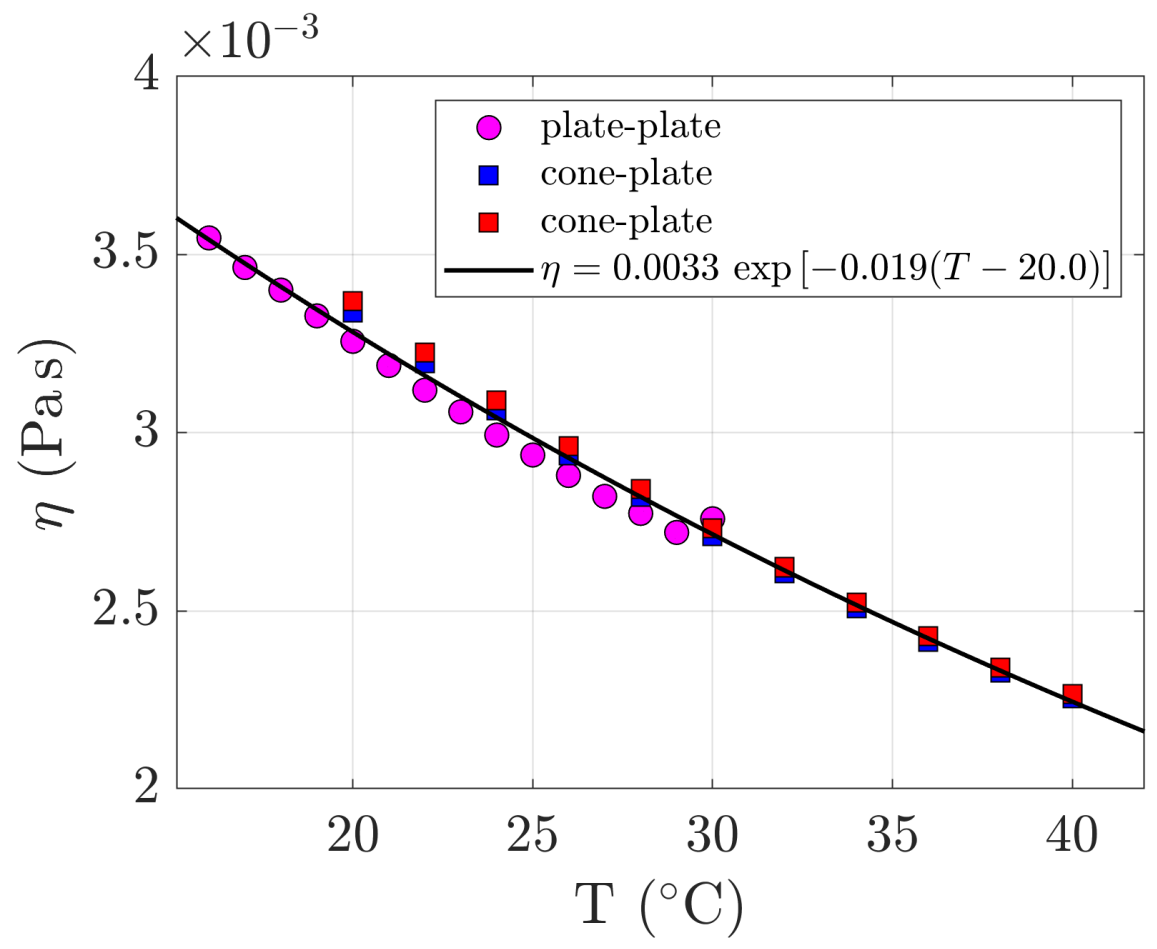

Figure 6: Viscosity of liquid hexadecane as a function of temperature obtained for different rheometer geometries. For measurements with plate-plate geometry (circles) we used a 60-mm-wide plate, the gap was fixed and equal to $1000 \mu \mathrm{m}$ and the imposed shear stress was $0.1 \mathrm{~Pa}$. In measurements with cone-plate geometry (squares), the cone angle was $2^{\circ}$, the gap was $70 \mu \mathrm{m}$ and the imposed shear stress was $0.1 \mathrm{~Pa}$. The black line is the data fit. 
(i.e. $0.2{ }^{\circ} \mathrm{C} / \mathrm{min}$ ). Moreover, in Fig. $7 \mathrm{c}$ the $\operatorname{ramp} 0.2^{\circ} \mathrm{C} / \mathrm{min}$ leads to a slightly smaller hysteresis than the one observed with DSC (grey region in the figure).

Beside the fact that a lower cooling rate can decrease the hysteresis because it ensures more time for crystals to nucleate and grow, one can also expect a dependence of $T_{s}$ on the imposed shear rate. Although shear flow can lead to a homogenization of temperature by advection (here the flow does not lead to recirculation), its main impact remains linked to the breakage of solid clusters and weak crystals. This is similar to what happens in weakly sheared hard-sphere colloids, where at low supersaturation, crystallization rate decreases as the strain rate increases [49]. This occurs when the forces exerted by the shear flow overcome the driving force of crystallization, leading to the breakage of the forming solid clusters. However, in the case of Fig. 7, we do not observe any relevant shifts of hexadecane's solidification temperature when varying $\dot{\gamma}$. A possible explanation is that even the lowest shear rate tested here $\left(\dot{\gamma}=0.1 \mathrm{~s}^{-1}\right)$ affects the system by breaking down crystals and weakening the forming solid structure as should be the case for higher $\dot{\gamma}$.

A way to reduce the influence of measurements on the phase transition process is to proceed to oscillatory tests. We carried out time sweep tests for both solidification and melting processes by imposing small stress amplitudes and by using a 40-mm-wide plate. Both the gap between plates (here equal to $1200 \mu \mathrm{m})$ and the frequency $\left(\omega=10 \mathrm{rads}^{-1}\right)$ are kept constant. Tests started from a liquid sample previously pre-sheared for around 5 minutes at $T=20^{\circ} \mathrm{C}$. In order to solidify the sample a decreasing temperature ramp of $1{ }^{\circ} \mathrm{C} / \mathrm{min}$ was then applied until the temperature reached $12{ }^{\circ} \mathrm{C}$. When the latter was achieved, the same increasing temperature ramp was applied from $12{ }^{\circ} \mathrm{C}$ to $20{ }^{\circ} \mathrm{C}$ in order to melt again the sample. In Fig. 8 we show the results obtained for an imposed amplitude stress of $\sigma=2 \mathrm{~Pa}$ (Fig. 8a) and $\sigma=0.2 \mathrm{~Pa}$ (Fig. 8b). Similarly, in Fig. 9 we show results achieved with a smaller temperature $\operatorname{ramp}\left(0.2^{\circ} \mathrm{C} / \mathrm{min}\right)$ and smaller stresses.

Within these experimental conditions, we clearly obtain in both cases a temperature hysteresis around the phase change. While the melting temperature is always close to that obtained with DSC, the solidification temperature varies considerably depending on the applied conditions. For a large temperature ramp (Fig. 8), $T_{s}$ is quite small and is found to be around $13{ }^{\circ} \mathrm{C}$ for both tested stresses. The resulting hysteresis is thus larger than the one from DSC. Similarly to what observed in rotational mode, by applying a slower 

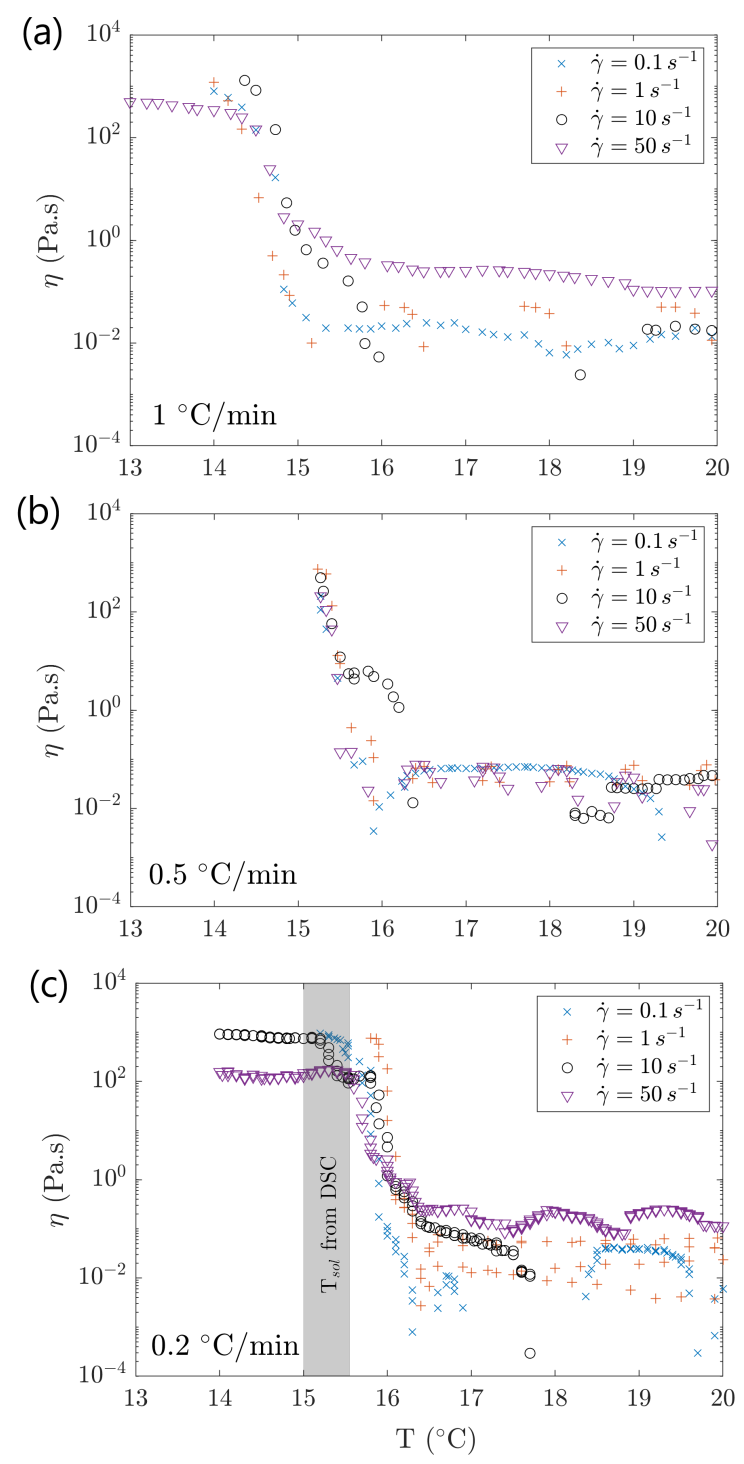

Figure 7: Variation of viscosity $\eta$ as a function of temperature $T$ from rotational test during the solidification of hexadecane. Three temperature ramps were used: a decrease of (a) $1.0{ }^{\circ} \mathrm{C} / \mathrm{min}$, (b) $0.5{ }^{\circ} \mathrm{C} / \mathrm{min}$ and (c) $0.2{ }^{\circ} \mathrm{C} / \mathrm{min}$. The gray box shows the interval of solidification temperature $T_{s}$ obtained from DSC (i.e. in between 15.0 and $15.5^{\circ} \mathrm{C}$ ). Different symbols represent different shear rates, $\dot{\gamma}=[0.1,1.0,10,50] \mathrm{s}^{-1}$. Data points represent the average of at least three runs with the same conditions. 
ramp instead (Fig. 9), the hysteresis significantly reduces and $T_{s}$ moves to a temperature around $16{ }^{\circ} \mathrm{C}$. However, it is still not easy to infer whether this thermal hysteresis is a real material property or it is mainly due to the chosen cooling rate and applied shear rate or stress. Differences between Fig. 8 and Fig. 9 remain crucial and they need to be taken into account once dealing with processes with fast temperature variations rather than with slow ones.

The complex viscosity, $\eta^{*}=\left(G^{\prime 2}+G^{\prime \prime 2}\right)^{1 / 2} \omega^{-1}$, and the viscosity, $\eta$, obtained from oscillatory and rotational measurements, respectively, are shown in Fig. 10 for a cooling rate of $0.2{ }^{\circ} \mathrm{C} / \mathrm{min}$. Here we present curves for rotational measurements with imposed strain rate of 0.1 and $50 \mathrm{~s}^{-1}$, together with those ones for oscillatory measurements with imposed stress of 0.2 and $0.02 \mathrm{~Pa}$. For this temperature ramp, between the two methods we observe only small differences in the temperature below which crystallization begins (less than $1{ }^{\circ} \mathrm{C}$ ). However, a larger discrepancy arises when looking at the value of viscosity achieved after the liquid-to-solid phase change: here it can span up to three orders of magnitude at, for instance, $T=14.0{ }^{\circ} \mathrm{C}<T_{s}$. These evidences suggest that even for such small shear stresses in oscillatory mode and strain rates in rotational mode, the conditions imposed by the rheometer have some significant influences on the nucleation and/or crystallization process.

\subsubsection{Steady temperature}

To avoid issues related with a too large temperature ramp we performed oscillatory time sweep tests at fixed temperature. This procedure allows to follow the transient behavior of the material at a given temperature and to obtain insights about time scales of the phase transition.

We focused on a short range of temperatures around the solidification temperature $T_{s}$ obtained by DSC, where very fine oscillatory tests with an imposed shear stress of $0.001 \mathrm{~Pa}$ were carried out. Although such a small imposed stress was chosen to investigate the beginning of crystallization and the solidification of the sample, we do expect it to be too small to obtain reliable data in liquid phase because of the low viscosity of liquid hexadecane. This is the reason of noisy results in liquid hexadecane in what follows. We worked with a frequency of $\omega=10 \mathrm{rad} \mathrm{s}^{-1}$, a gap of $1000 \mu \mathrm{m}$ and a $40-\mathrm{mm}$ diameter plate. Given the long duration of each run, during the measurement we used an anti-evaporation device that covered the moving plate and the sample. Each experiment started with a liquid sample of hexadecane at initial temperature $T_{0}=20.0{ }^{\circ} \mathrm{C}$ to which a single temperature step was then 

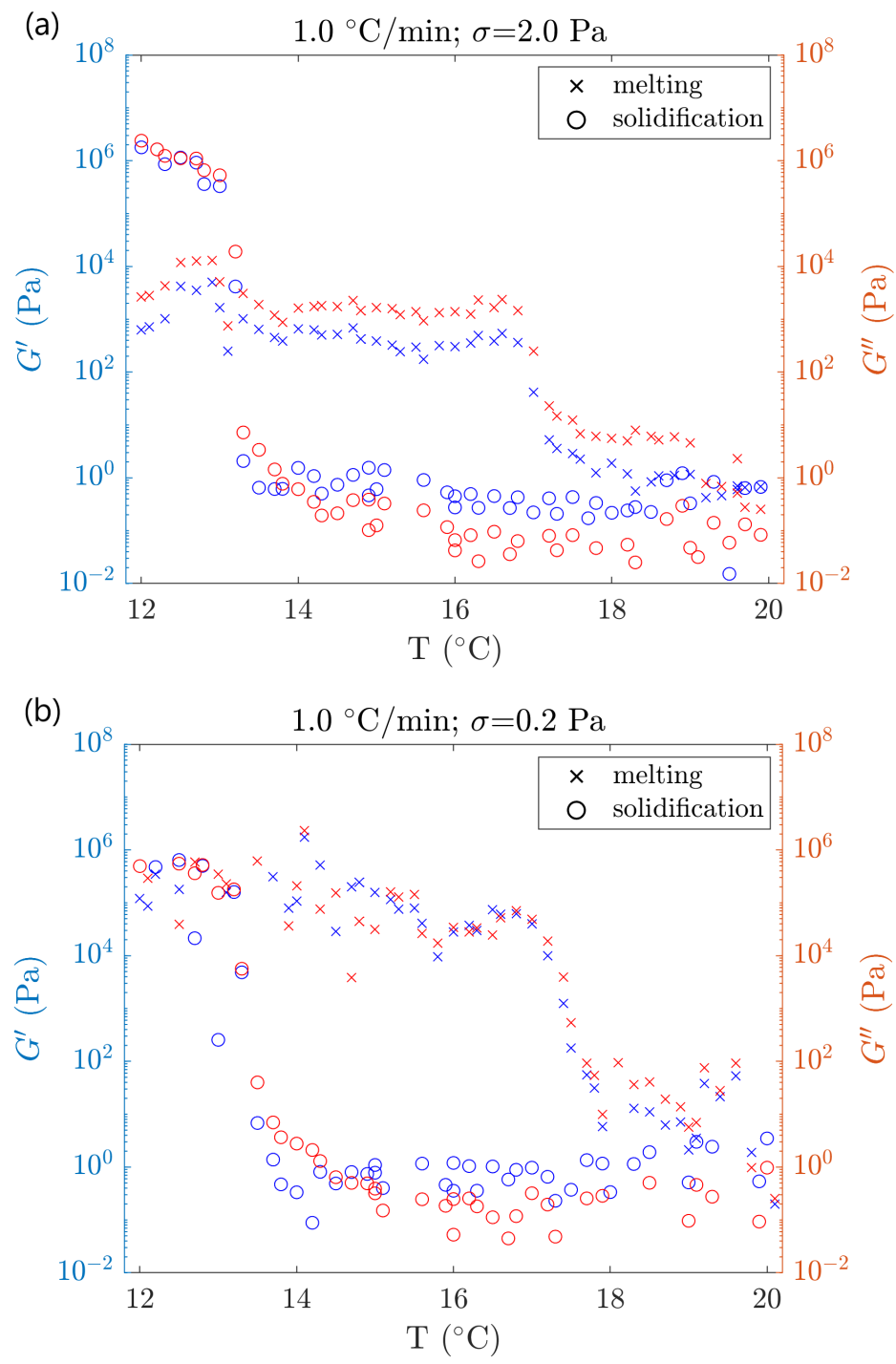

Figure 8: Hexadecane's temperature dependence of storage $G^{\prime}$ (blue symbols) and loss $G^{\prime \prime}$ (red symbols) moduli during melting (crosses) and solidification (circles) processes, for imposed stress of $2.0 \mathrm{~Pa}$ (a) and $0.2 \mathrm{~Pa}$ (b). The initial liquid sample was first solidified and then remelted by using a temperature ramp of $1{ }^{\circ} \mathrm{C} / \mathrm{min}$. 

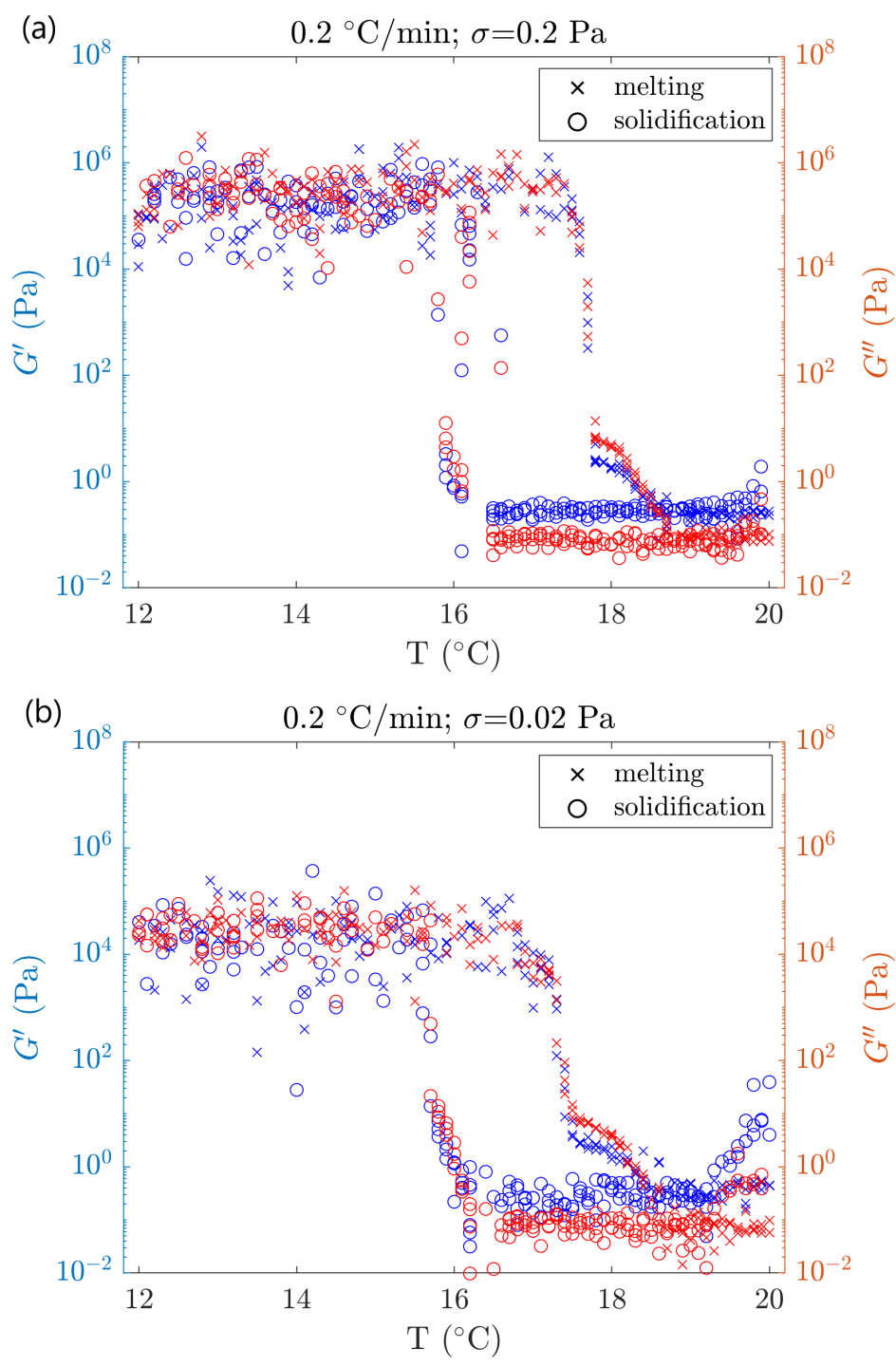

Figure 9: Hexadecane's temperature dependence of storage $G^{\prime}$ (blue symbols) and loss $G^{\prime \prime}$ (red symbols) moduli during melting (crosses) and solidification (circles) processes, for imposed stress of $0.2 \mathrm{~Pa}$ (a) and $0.02 \mathrm{~Pa}$ (b). The initial liquid sample was first solidified and then remelted by using a temperature ramp of $0.2^{\circ} \mathrm{C} / \mathrm{min}$. 


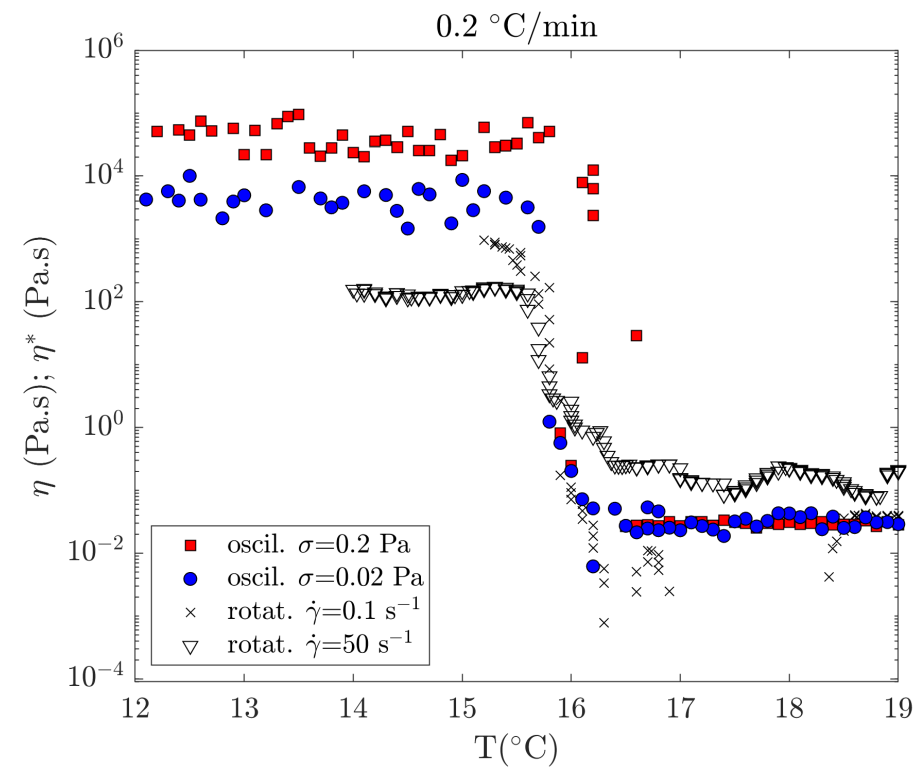

Figure 10: Temperature dependence of viscosity $\eta$ and complex viscosity $\eta^{*}$ for solidification processes with temperature ramp of $0.2{ }^{\circ} \mathrm{C} / \mathrm{min}$. The complex viscosity is retrieved for oscillatory tests with imposed stress of 0.2 and 0.02 Pa. For rotational tests we show the cases with constant shear rate of 0.1 and $50 \mathrm{~s}^{-1}$. 
applied, i.e. temperature was decreased from $T_{0}$ directly to the desired value (see an example in the inset of Fig. 11a).

In Fig. 11 we show for an imposed temperature of $T=15.0{ }^{\circ} \mathrm{C}$ the time evolution of $G^{\prime}$ and $G^{\prime \prime}$ and the one of the normal force exerted by the sample on the upper plate of the system. Three main material responses can be observed from the curves of the moduli (Fig. 11a). The first step (i) regards a noisy stage that lasts a couple of minutes in which the sample is still fully liquid. In the second step (ii), that starts after about three minutes, the structure seems to change and the material response shows an overall liquid behavior where its viscous component is larger than the elastic one $\left(G^{\prime \prime}>G^{\prime}\right)$. The last step (iii) starts around 8-10 minutes after the beginning, when the crossover between $G^{\prime}$ and $G^{\prime \prime}$ takes place. Here the sample behavior is prevailed by its solid-elastic response with values of storage modulus $\left(G^{\prime} \sim 25\right.$ $\mathrm{Pa})$ and loss modulus $\left(G^{\prime \prime} \sim 18 \mathrm{~Pa}\right)$ that remain constant till the end of the run. The same behavior is shown in Fig. 12 at three other temperatures, i.e $T=14.5,15.5$ and $16.0^{\circ} \mathrm{C}$. For each case we see the same three stages described above, with a solid-elastic behavior that becomes more pronounced with time. We were able to detect the crossover between $G^{\prime}$ and $G^{\prime \prime}$ until $T=16.0^{\circ} \mathrm{C}$, but not for higher temperatures. Although for $T=16.0^{\circ} \mathrm{C}$ the difference between $G^{\prime}$ and $G^{\prime \prime}$ remains very small (only few Pa), this latter temperature is much like the apparent solidification temperature obtained from rotational and oscillatory tests with temperature ramp of $0.2{ }^{\circ} \mathrm{C} / \mathrm{min}$ (Fig. 10).

Changes also occur in the slope of the normal force during the mention stages (Fig. 11b and Fig. 12b). For instance, during stage (ii) the normal force decreases due to the sample volume reduction caused by sample crystallization (Fig. 11b). However, in stage (iii) the reduction in volume is countered by an increment of normal force. The latter can be related to crystals being formed that push against the upper plate of the rheometer. After this increment, the value of normal force seems also to vary cyclically around a mean constant value. These cycles are characterized by periods where the normal force decreases almost linearly with a step-like behavior. We point out that the period of such cycles is around a couple of minutes, thus it is not linked to the oscillation period of the rheometer that is $2 \pi \omega^{-1}=0.63$ s. Such variation of normal force most likely highlights phenomena at the plate-sample interface. Indeed, at $T=16.0^{\circ} \mathrm{C}$ we observed by eyes the sample being in its solid phase except on its upper surface where a thin layer of liquid phase persists. This thin liquid layer was very likely due to the friction with 
the moving plate.

These evidences indicate that even at this weak imposed stress $(0.001 \mathrm{~Pa})$, corresponding to low strains (ranging from $10^{-3}$ to $10^{-5}$ after the crossover point between $G^{\prime}$ and $G^{\prime \prime}$ ), and long waiting time, an imposed oscillation affects constantly the solidification process by breaking the forming crystals at least nearby the moving plate for temperatures near the transition. This results in a weaker structure compared to that obtained for lower temperatures, as highlighted by the low values of $G^{\prime}$ and $G^{\prime \prime}$ observed in Fig. 11a with respect to those obtained with small temperature ramps in the solid phase (e.g. in Fig. 9).

\section{System at rest and local investigation with Raman spectroscopy}

The onset of hexadecane's phase change was also investigated for the system at rest (i.e. without any imposed deformation) by Raman spectroscopy. This spectroscopy technique is based on the inelastic scattering of light and it allows the investigation of spectra that are directly linked to vibrational modes of the chemical bonds present in the analyzed sample's molecules.

In order to collect scattered light at different temperatures, a setup consisting of a copper plate laying on a Peltier element was used (Fig. 13). A $15.0 \mathrm{~mm}$-deep and $37.7 \mathrm{~mm}$-wide square cavity was made in the center of the plate. The cavity lateral surface has an average roughness of $R_{a}=0.60$ $\mu \mathrm{m}$, while the average roughness of the bottom surface is $R_{a}=1.60 \mu \mathrm{m}$. The cavity was filled by around $16 \mathrm{~mL}$ of hexadecane to form a $\sim 11 \mathrm{~mm}$-high fluid layer with a free upper surface. Isothermal conditions were obtained in the bulk sample by adding a thick layer of insulating foam around the lateral walls of the device and a glass surface on the top of the system as represented in Fig. 13. This latter glass plate has a thickness of $0.55 \mathrm{~mm}$ and a transmittance of $90.5 \%$ at the laser wavelength (see supplementary materials). Hexadecane was then cooled or heated to the chosen temperature and kept at that constant temperature for several hours before acquiring the spectra. Temperature was recorded by a PT100 platinum resistance thermometer placed inside the lower part of the copper plate as indicated in Fig. 13. The distance between the bottom of the sample reservoir and the central axis of the thermometer is $3.8 \mathrm{~mm}$. When the liquid sample was solidified, crystallites formed far from cavity walls were usually small (mm-scale) and randomly oriented. 

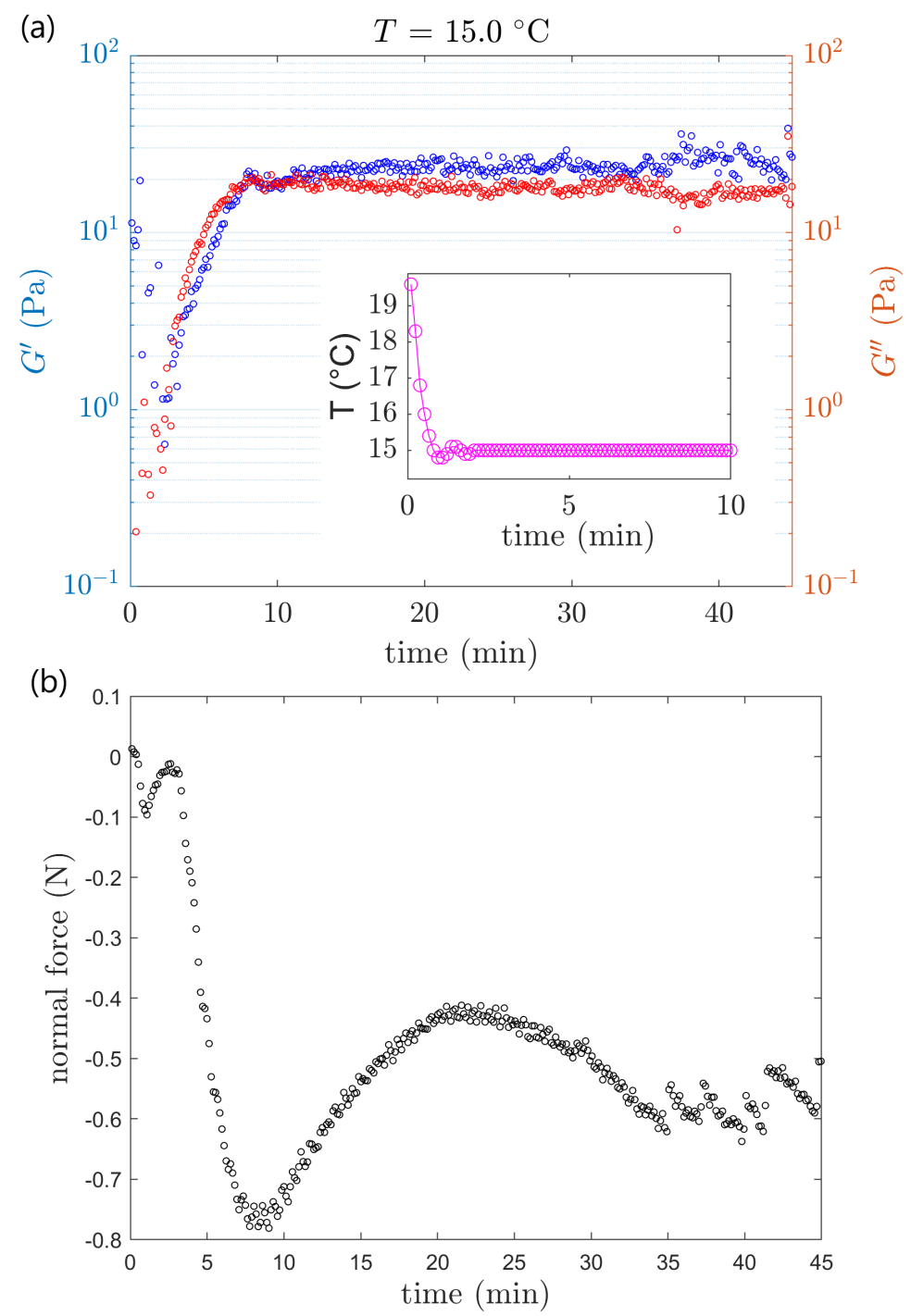

Figure 11: Oscillatory time sweep with imposed stress of $0.001 \mathrm{~Pa}$ and gap of $1000 \mu \mathrm{m}$. Temperature is decreased by a single step from $T_{0}=20.0^{\circ} \mathrm{C}$ to $T=15.0^{\circ} \mathrm{C}$ and kept constant afterwards as shown by the inset in (a). (a) Time evolution of the storage modulus $G^{\prime}$ (blue) and loss modulus $G^{\prime \prime}$ (red). (b) Time evolution of the normal force. 

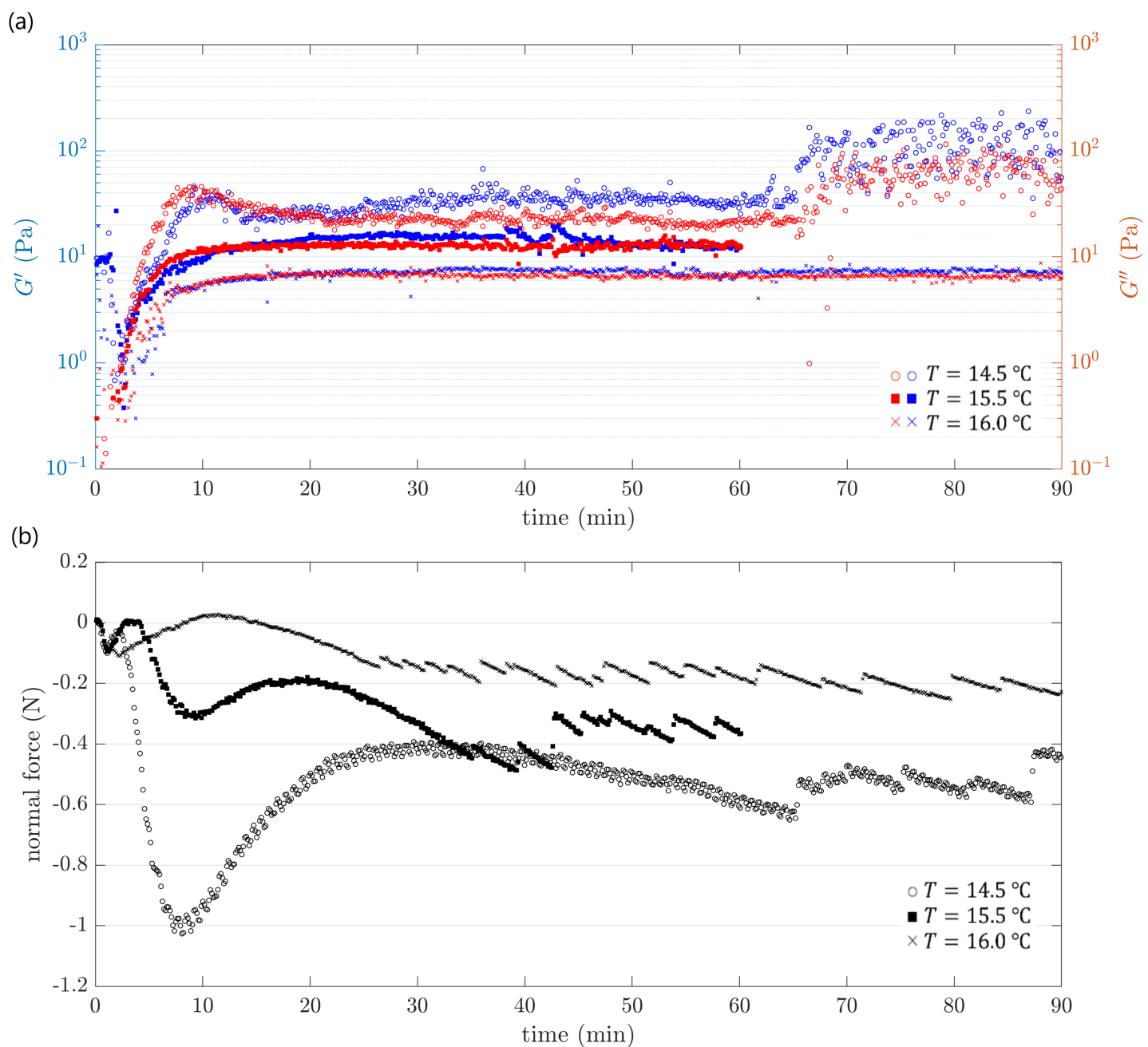

Figure 12: Oscillatory time sweep with imposed stress of $0.001 \mathrm{~Pa}$, gap of $1000 \mu \mathrm{m}$, and for temperatures of $T=14.5$ (circles), 15.5 (squares) and $16.0^{\circ} \mathrm{C}$ (crosses). (a) Time evolution of the storage modulus $G^{\prime}$ (blue) and loss modulus $G^{\prime \prime}$ (red). (b) Time evolution of the normal force. 


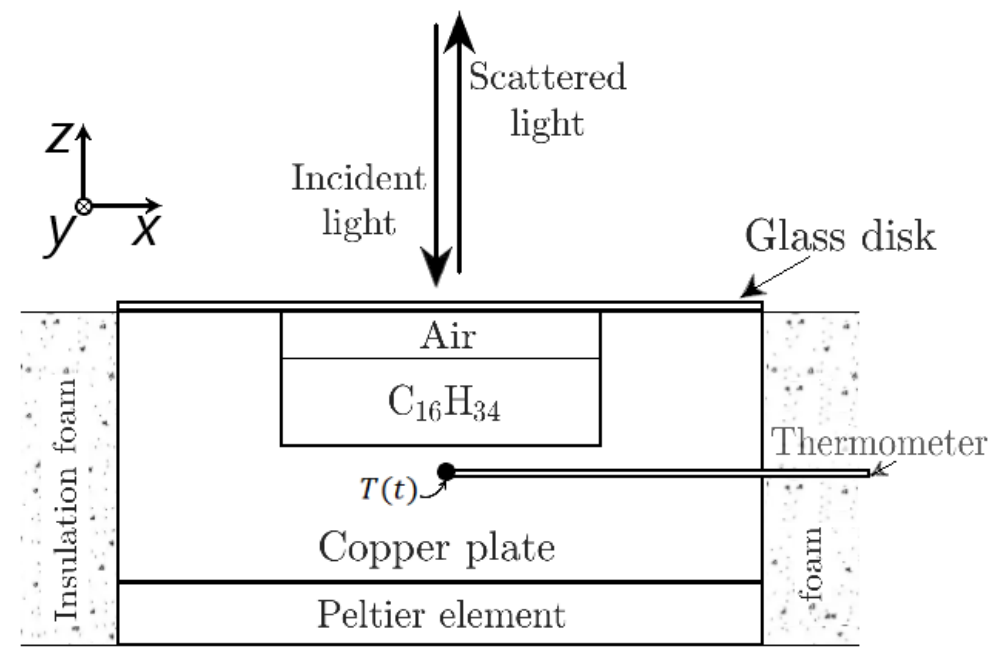

Figure 13: Heating and cooling system for Raman analysis. $T(t)$ indicates the point where temperature is recorded.

Laser beam with wavelength equal to $532 \mathrm{~nm}$ (power $\sim 25 \mathrm{~mW}$ ) was focused on the top of the sample layer. The laser excited the sample only during the acquisition of the spectra (acquisition time of $1000 \mathrm{~ms}$ ) in order to avoid any additional heating. The scattered light from the sample was finally collected by a spectrograph (HRS-750 Princeton Instruments) with entrance slit width of $200 \mu \mathrm{m}$ and grating of 600 lines per $\mathrm{mm}$. All spectra were here acquired with a 10x objective and with accuracy of $1.5 \mathrm{~cm}^{-1}$.

The first way to identify the phase transition with Raman spectroscopy is through the observation of how peaks intensity and position change with temperature and time.

We focused our spectra analysis within the $\mathrm{CH}_{2}$ and $\mathrm{CH}_{3}$ stretching region of hexadecane's Raman spectra. It corresponds to the interval of Raman shift from around 2800 to $3100 \mathrm{~cm}^{-1}[50,51]$. Within this region, the band near to $2850 \mathrm{~cm}^{-1}\left(P_{1}\right)$ and the one near to $2885 \mathrm{~cm}^{-1}\left(P_{2}\right)$ correspond to the $\mathrm{CH}_{2}$ symmetric and asymmetric molecule stretching, respectively. Bands near $2930 \mathrm{~cm}^{-1}\left(P_{3}\right)$ and $2957 \mathrm{~cm}^{-1}\left(P_{4}\right)$ are instead due to the $\mathrm{CH}_{3}$ symmetric and asymmetric stretching, respectively [40].

\subsection{Raman spectra of solid and liquid phases}

Peaks intensity within the $\mathrm{CH}$ region is displayed in Fig. 14 for solid hexadecane at $T=12.0{ }^{\circ} \mathrm{C}$ (Fig. 14a) and liquid hexadecane at temperature 
$T=18.5,19.7$ and $30.0^{\circ} \mathrm{C}$ (Fig. 14b).

A main difference between spectra of solid (Fig. 14a) and liquid phase (Fig. 14b) concerns peaks $P_{1}$ and $P_{2}$. In solid phase, $P_{2}$ is always obtained more intense than $P_{1}$, leading to a ratio $P_{2} / P_{1}$ larger than one $\left(P_{2} / P_{1}=1.07\right.$ for the case in Fig. 14a), while in liquid hexadecane $P_{2}$ becomes wider and smaller than $P_{1}\left(P_{2} / P_{1}=0.89\right.$ in Fig. 14b). Similarly, peaks of $\mathrm{CH}_{3}$ stretching also change during the phase transition. Both peaks for the $\mathrm{CH}_{3}$ symmetric stretching $\left(P_{3}\right)$ and $\mathrm{CH}_{3}$ asymmetric stretching $\left(P_{4}\right)$ are narrower and easier to recognize in the solid phase than in the liquid phase. The evolution of Raman peaks intensities can be used as a marker of phase transition, as shown by Duričković et al. [52]. Indeed, they shown that the water-ice phase change can be determined by following the ratio of intensities of main peaks (i.e. the most intense one and the one that changes most significantly during the transition) for different spectral bands. They shown that the determination of solidification temperature and the identification of the two phases was possible by following the peak intensities ratio obtained both from the intensities at fixed wavenumbers and from integrated intensities of wavenumbers ranges (as long as the characteristic wavenumbers of the two phases were included). The same method was afterwards employed also to determine the concentration of salt in aqueous solutions [53, 54].

\subsection{Evolution of Raman spectra during solidification}

Figure $15 \mathrm{a}$ shows the evolution of the ratio $P_{2} / P_{1}$ during the solidification of hexadecane as temperature decreases. The initially liquid sample was cooled by decreasing the temperature with steps of $\sim 0.2{ }^{\circ} \mathrm{C}$ separated from each other by several hours. Color bars in the figure refer to the time (in hours) elapsed between the change in temperature and the acquisition of the scan. All Raman scans were here performed at fixed position without moving the setup throughout the duration of the experiment. The ratio between $P_{2}$ and $P_{1}$ for the liquid phase remains constant around 0.86 until the temperature reaches $T=17.3^{\circ} \mathrm{C}$. At this temperature, hexadecane locally begins to crystallize since $P_{2} / P_{1}$ slowly increases. The difference from the ratio associated to the purely liquid phase starts to be more clear after a waiting time of around 24 hours from the previous temperature change. After around 72 hours $P_{2} / P_{1}$ reaches the value of 0.98 , marking a significant difference with the constant value obtained in the liquid phase for higher temperatures. A similar trend is also observed at $T=17.1{ }^{\circ} \mathrm{C}$ where $P_{2} / P_{1}$ further increases with time and only after $\sim 4$ hours reaches a steady value. For $T \leq 16.9^{\circ} \mathrm{C}$ 

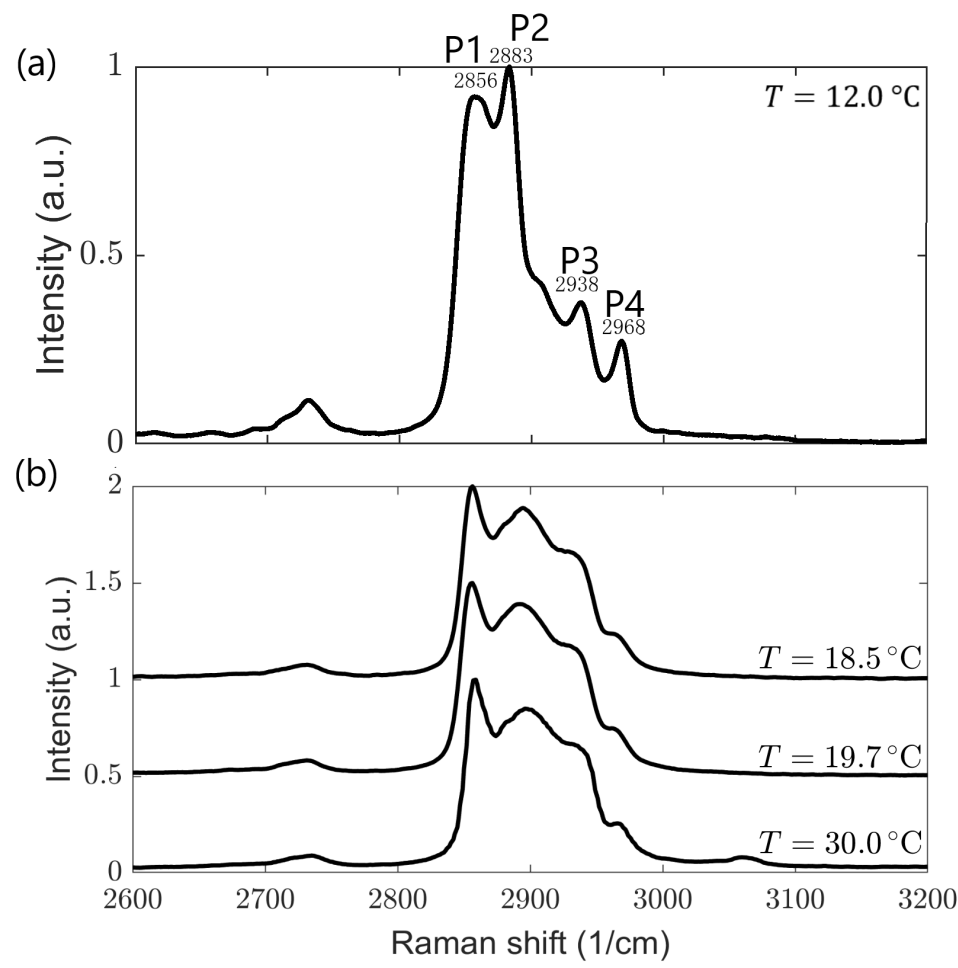

Figure 14: Raman spectra of hexadecane within the $\mathrm{CH}$ region. (a) Solid phase at $T=12.0$ ${ }^{\circ} \mathrm{C}$; (b) liquid phase at $T=18.5,19.7$ and $30.0{ }^{\circ} \mathrm{C}$. $P_{1}$ represents the peak associated to the $\mathrm{CH}_{2}$ symmetric stretching $\left(\sim 2856 \mathrm{~cm}^{-1}\right), P_{2}$ the peak associated to the $\mathrm{CH}_{2}$ asymmetric stretching $\left(\sim 2883 \mathrm{~cm}^{-1}\right), P_{3}$ the peak associated to the $\mathrm{CH}_{3}$ sym. stretching $(\sim 2938$ $\left.\mathrm{cm}^{-1}\right), P_{4}$ the peak associated to the $\mathrm{CH}_{3}$ asym. stretching $\left(\sim 2968 \mathrm{~cm}^{-1}\right)$. 
the dependence of $P_{2} / P_{1}$ on the waiting time seems to be no longer so relevant and the value of the ratio between peak intensities settles down around a new constant value.

Besides the intensity ratio, also the position of peak $P_{2}$ evolves both in time and temperature (Fig. 15b). In fact, although the intensity of a Raman peak depends on the concentration of the oscillators, the position of the peak is defined by the frequency of the oscillation. Therefore, peak's intensity and position correspond to different properties from a physical point of view, and both of them can be useful to identify the phase transition. In our case, a strong transition is recognizable for peak $P_{2}$ at $T=17.3{ }^{\circ} \mathrm{C}$ where it moves from around $2896 \mathrm{~cm}^{-1}$ to around $2882 \mathrm{~cm}^{-1}$. The transition at this temperature is not abrupt, instead with increasing waiting time the peak slowly proceeds toward the solid phase position in a similar way to what observed for $P_{2} / P_{1}$.

\subsection{Differences between melting and solidification}

Reciprocally, similar experiments were conducted for the solid-to-liquid transition. Results are depicted in Fig. 16 in terms of $P_{2} / P_{1}$ as a function of temperature for different melting experiments (triangles) and different solidification experiments (circles). For the melting process, the local transition takes place at $T_{m}=17.7^{\circ} \mathrm{C}$, i.e. when the ratio $P_{2} / P_{1}$ becomes smaller than 1. This transition occurs over shorter times than the crystallization process. The evolution of peaks within the $\mathrm{CH}$ region that we obtained during the solid-to-liquid transition is in agreement with experiments of Corsetti et al. [40], whom reported for the melting of hexadecane an almost instantaneous transformation in Raman spectra at $T=18.1^{\circ} \mathrm{C}$.

As previously noted, within the experimental conditions of the first solidification process carried out (red circles in Fig. 16), solidification starts around $T=17.3^{\circ} \mathrm{C}$ if enough time is waited. Below this temperature we obtain $P_{2} / P_{1}>1$, meaning that the threshold value $P_{2} / P_{1}=1$ can be used as a criterion to distinguish between liquid and solid phase. In this way we observe a very small hysteresis between melting and solidification temperatures. This difference could be further reduced by inducing crystals nucleation via additional perturbations at interfaces. This latter point will be investigated deeply in a future work.

Following a similar solidification protocol but with larger temperature steps (green circles in Fig. 16), the increase in $P_{2} / P_{1}$ occurs at $T=17.0$ ${ }^{\circ} \mathrm{C}$. As highlighted in Fig. 16, here at point 'A' the ratio $P_{2} / P_{1}$ is smaller 

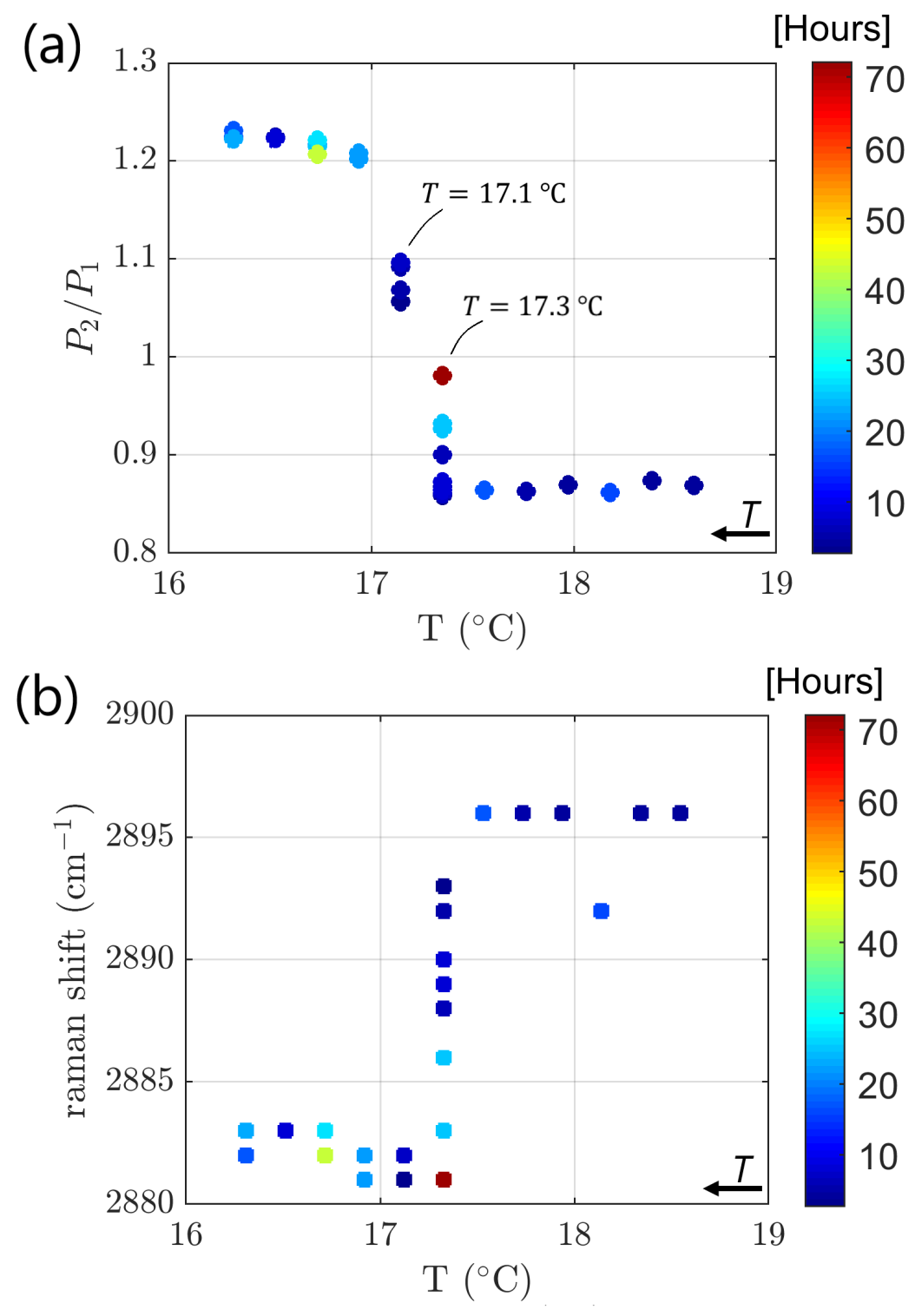

Figure 15: Evolution of Raman peaks intensity and position during hexadecane solidification. Starting from a liquid sample at $T=18.6{ }^{\circ} \mathrm{C}$, temperature was decreased to $T=16.3$ ${ }^{\circ} \mathrm{C}$ with steps of around $0.2{ }^{\circ} \mathrm{C}$. Color bars indicate the waiting time (in hours) between the change in temperature and the acquisition of the scan. The longest waiting time is $\sim 72$ hours at $T=17.3{ }^{\circ} \mathrm{C}$. (a) Variation of the ratio between the intensity of the peak associated to the $\mathrm{CH}_{2}$ asymmetric stretching $\left(P_{2}\right)$ and the intensity of the peak associated to the $\mathrm{CH}_{2}$ symmetric stretching $\left(P_{1}\right)$ as a function of temperature and time. (b) Raman shift of peak $P_{2}$ as a function of temperature and time. 
than 1 (corresponding to liquid phase), while at point ' $\mathrm{B}$ ' it becomes larger than 1 (corresponding to solid phase). This variation took place in $\sim 5.5$ hours, pointing out that the solidification process requires shorter times in the subcooled region, i.e. below $T=17.3{ }^{\circ} \mathrm{C}$.

Additionally, although we observe that $P_{2} / P_{1}$ remains constant in the liquid phase, it can take different values in the solid phase as shown in Fig. 16. This can be due either to (1) the formation of differently oriented crystals [55], or (2) the presence of both crystalline and glass phase [56]. We deal with this in the next section where a description of only the solid phase of hexadecane is given. However, given the large variety of $P_{2} / P_{1}$ in the solid phase that could affect a correct choice of the transition temperature, one should also consider how other characteristics of the spectra vary and evolve as temperature changes.

We carry out the principal component analysis (PCA) for all scan acquired to evaluate if the entire set of Raman spectra in the $\mathrm{CH}$-region changes during the phase transition congruently with $P_{2} / P_{1}$. PCA allows us to reduce dimensionality of a data set with large number of variables and to find specific aspects that represent the variance of the data. By using PCA the large number of variables needed to originally describe the data set (i.e. all the wavenumbers) can indeed be reduced to just a few new variables (i.e. the principal components) which account for the majority of its variability. Once the principal components that characterize the entire set of acquired spectra are extracted, each spectra can be represented in the principal component space by its principal component scores. In the principal component space the identification of similar spectra from the very different ones is done by discerning how they are clustered together.

As pointed out by [39], the use of PCA over peak intensity ratio brings some advantages in studying the phase transition of a PCM. For instance, to calculate an intensity ratio representative of phase change one must identify the correct spectral bands that characterize the transition (e.g. $P_{1}$ and $P_{2}$ in the $\mathrm{CH}$-region for hexadecane). This can introduce a threshold of subjectivity as it makes it necessary to correctly determine those peaks that properly suite the analysis. Moreover, as shown in Fig. 15b, in addition of peaks intensities the phase transition leads to variations in peaks position. Hence, the accuracy in determining peak positions can also have an influence on the correct estimation of intensity ratio. Although for hexadecane this seems to not affect the identification of the transition, it may become necessary to consider this shift when working with other PCMs. In this case, it should 


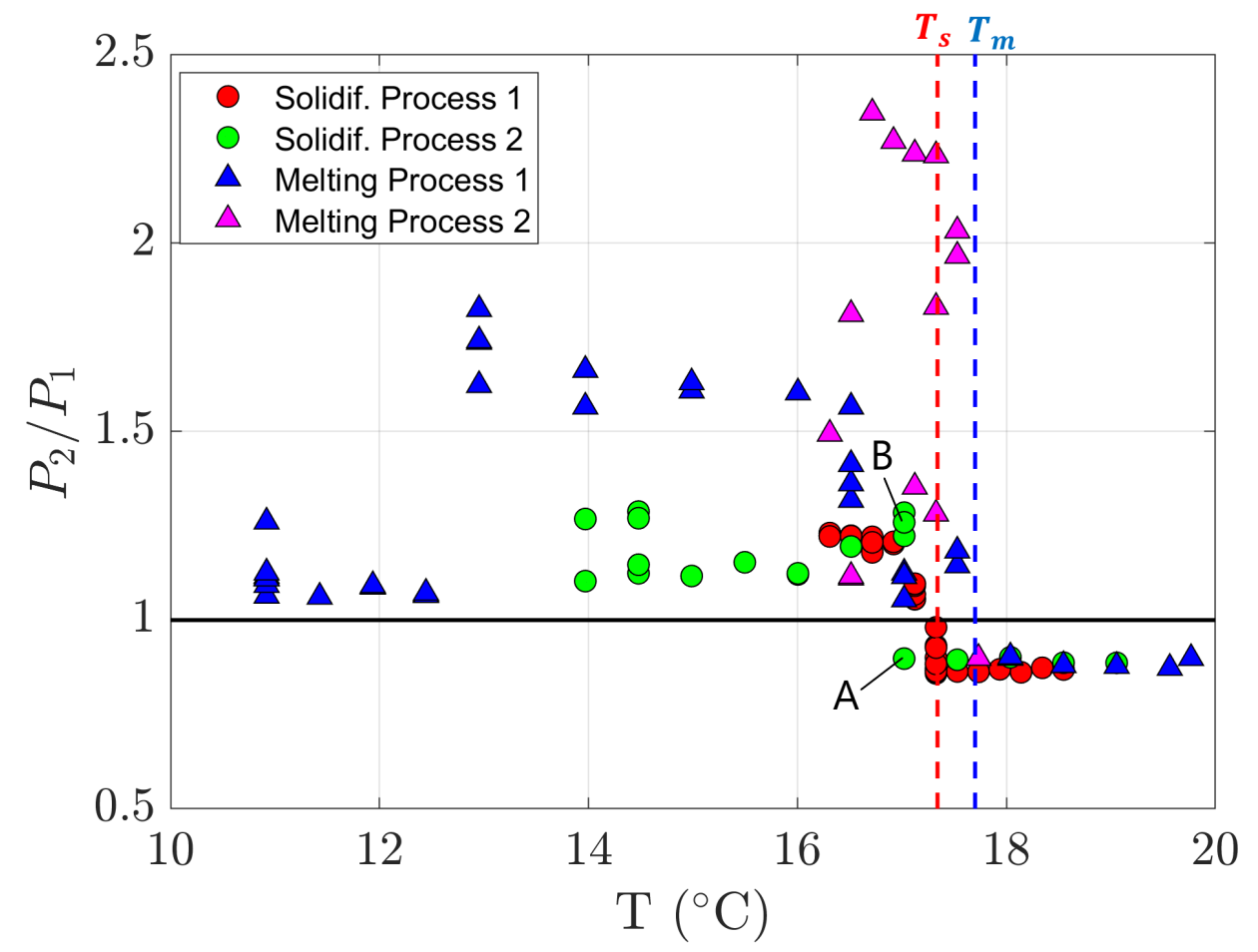

Figure 16: Ratio of Raman peaks intensity $P_{2} / P_{1}$ as a function of temperature during the solidification (circles) and melting (triangles) of hexadecane. Colors refer to different runs of experiments. Red dashed line highlights the solidification temperature $T_{s}=17.3$ ${ }^{\circ} \mathrm{C}$, defined when $P_{2} / P_{1}$ starts to increase from the constant value in the liquid phase. For the solidification process shown in green, letter ' $\mathrm{A}$ ' and letter ' $\mathrm{B}$ ' correspond to $T=17.0$ ${ }^{\circ} \mathrm{C}$ and a waiting time of $\sim 3$ hours and $\sim 5.5$ hours, respectively. Blue dashed line is the melting temperature $T_{m}=17 .{ }^{\circ} \mathrm{C}$ obtained once $P_{2} / P_{1}<1$ in the melting processes. 
be more appropriate to calculate an intensity ratio based on integrated intensities rather than on a single wavenumber. Furthermore, the variation in peak intensity ratio during the transition could be also covered from a small signal-to-noise ratio, which is not the case in our experiments. As a consequence, for a more optimized phase identification, for instance during on-line monitoring of which PCMs phase is present at a given temperature in TES systems, a PCA analysis should be considered.

The first principal component $\left(\mathrm{PC}_{1}\right)$ and the second principal component $\left(\mathrm{PC}_{2}\right)$ of all the acquired spectra are shown in Fig. 17a and Fig. 17b, respectively. Together they cover $99.5 \%$ of variability, with $\mathrm{PC}_{1}$ that covers the $83.9 \%$ of it and $\mathrm{PC}_{2}$ the $15.6 \%$. The scatterplot of the scores for the first two principal components is given in Fig. 18. A main cluster of points is recognizable (bounded by the gray dashed line in Fig. 18) and corresponds to spectra of the liquid phase. Indeed, this cluster gathers together all those spectra acquired for $T \geq 17.7{ }^{\circ} \mathrm{C}$ and even for $T>17.3^{\circ} \mathrm{C}$ during a cooling procedure. Below these temperatures the sample is in solid phase but a main cluster is not recognizable.

The temperature values for which data points group together in the liquid phase cluster correspond to those find previously in Fig. 16 by looking at the variation of $P_{2} / P_{1}$. The clustering in the principal component space of these spectra suggests that the use of $P_{2} / P_{1}=1$ as a method to discern between solid and liquid phase can be appropriate at least for hexadecane.

Moreover, similarly for what observed from the plot of $P_{2} / P_{1}$ as a function of temperature, also in Fig. 18 one can notice the dependence on the waiting time of spectra acquired during the solidification at temperature close to the transition. For instance, freezing hexadecane at $T=17.0^{\circ} \mathrm{C}<T_{s}$ leads to a departure of the spectra from the liquid phase cluster only if a very long waiting time is waited before acquisition (more than 3 hours in our case). The same shift of spectra from the liquid phase cluster toward the solid phase can be followed for solidification at temperature $T=17.3{ }^{\circ} \mathrm{C}>T_{s}$. For this case, while the first spectra acquired after waiting 8 hours falls in the liquid phase cluster, the others move further and further apart from it as the waiting time increases.

\subsection{Polarized Raman in solid phase}

Hexadecane crystals have a triclinic structure, that is unequal crystallographic axes that are non-orthogonal to each other. As others even-numbered 


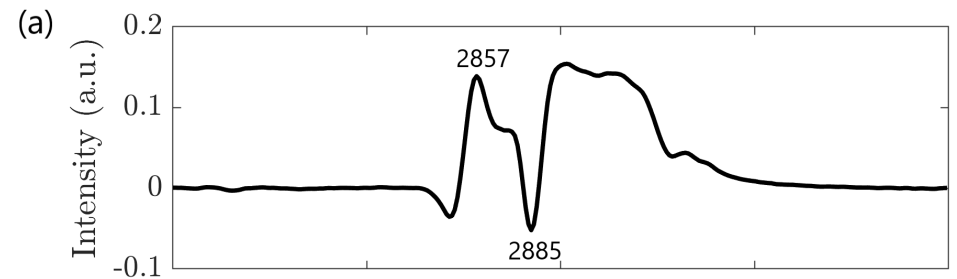

(b)

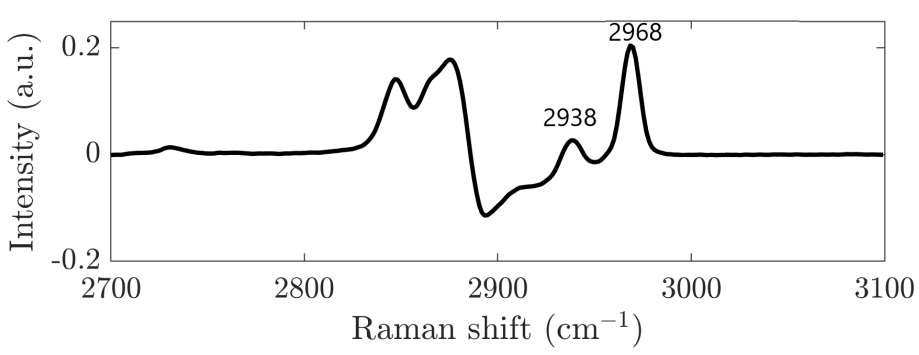

Figure 17: (a) First principal component $\mathrm{PC}_{1}$ and (b) second principal component $\mathrm{PC}_{2}$ for Hexadecane's Raman spectra in the $\mathrm{CH}$ stretching region.

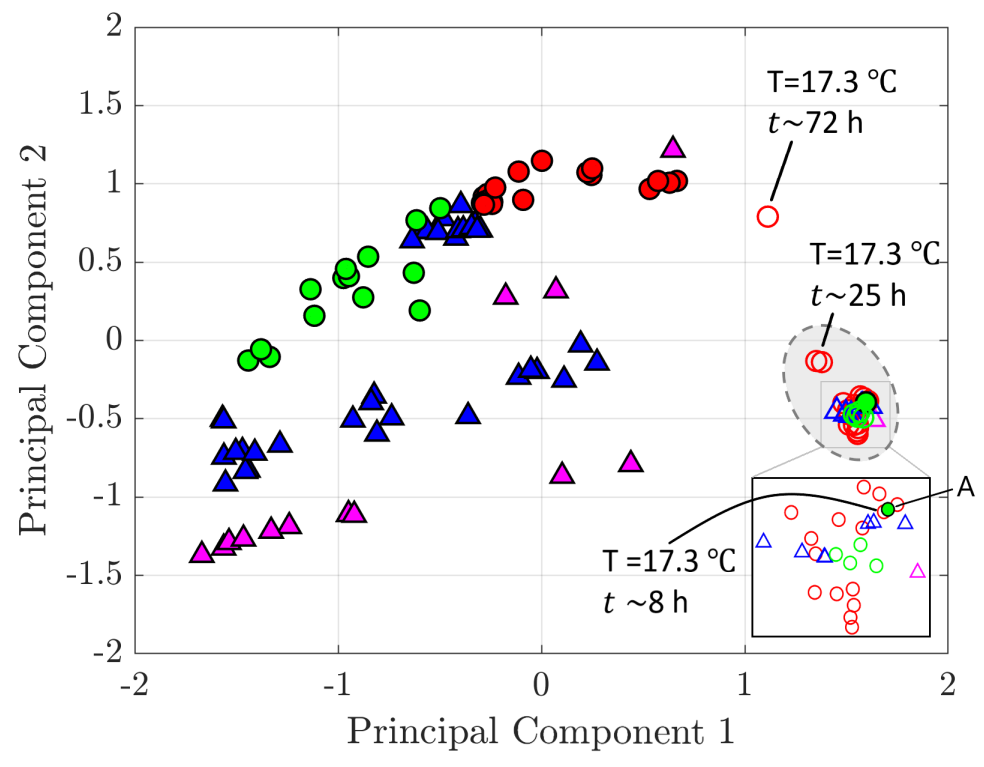

Figure 18: PCA scores plot. Colors and symbols are those of Fig. 16. For the solidification process: filled symbols are defined for $T \leq 17.1{ }^{\circ} \mathrm{C}$ while empty symbols for $T>17.1{ }^{\circ} \mathrm{C}$. For the melting process: filled symbols are for $T<17.7^{\circ} \mathrm{C}$ and empty symbols for $T \geq 17.7$ ${ }^{\circ} \mathrm{C}$. The inset is a zoom on part of the liquid phase cluster. The latter is bounded by the gray dashed line. Letter ' $\mathrm{A}$ ' is defined as in Fig. 16, i.e. $T=17.0^{\circ} \mathrm{C}$ and a waiting time of $\sim 3$ hours. 
$n$-alkanes with $n<20$, solid hexadecane also does not present any intermediate phases besides its crystalline triclinic phase and the liquid phase [40, 57].

We performed polarized Raman spectroscopy in a solid sample of hexadecane to verify if the large variability of spectra in solid phase observed in Fig. 16 may be due to the different orientations of crystals in the sample. By using the same setup described previously, we kept a thin layer of hexadecane (around $2 \mathrm{~mm}$ thick) at constant temperature $T=14.0^{\circ} \mathrm{C}$ for the entire analysis. Spectra were acquired after allowing the sample to crystallize completely (i.e. after more than 20 hours after setting the temperature) with a laser power of $\sim 50 \mathrm{~mW}$ and a $40 \times$ objective in order to focus on a small region. All other parameters were kept the same as those described at the beginning of this section.

We use the Porto notation based on the setup's coordinate system (defined as depicted in Fig. 13) instead of the sample's coordinate system to describe directions of incident and scattered light. Although this is a standard procedure when working with liquids (i.e. isotropic samples), we keep it also for the solid phase since orientations of crystallites are here unknown. Four polarization tensors can then be examined. The first writes as $Z(Y X) \bar{Z}$ and indicates light incident along $Z$ axis with laser polarized parallel to $Y$ axis, and scattering light in the $Z$ direction but in the opposite sense $(\bar{Z})$ with the analyzer aligned parallel to $X$ axis. Thus the other combinations are $Z(Y Y) \bar{Z}, Z(X X) \bar{Z}$ and $Z(X Y) \bar{Z}$.

In Fig. 19 we report the variation within the $\mathrm{CH}$-region of Raman spectra obtained in two distinct and fixed points of investigation. Although in all cases we observe $P_{2} / P_{1}>1$, meaning that no liquid phase is present, the value of $P_{2} / P_{1}$ depends on the geometry of polarization used to acquire the scan. It ranges between 1.57 and 2.28 in Fig. 19a and between 1.10 and 3.76 in Fig. 19b. It is the same range of $P_{2} / P_{1}$ we collected and shown for solid phase during the melting and solidification processes (Fig. 16). Beside the variation of $P_{2} / P_{1}$, the most pronounced difference observed when changing the polarization geometry regards peaks associated with the $\mathrm{CH}_{3}$ stretching vibration modes. In Fig. 19a a strong increment in intensity is recorded for the $\mathrm{CH}_{3}$ asymmetric stretching peak $\left(P_{4}\right)$ when the $Z(X Y) \bar{Z}$ geometry is employed. However, the same behavior does not occur at each acquisition spot, for instance in Fig. 19b both $P_{3}$ and $P_{4}$ remain always much less intense and developed than $P_{1}$ and $P_{2}$.

To conclude, the variations of Raman spectra observed in the solid phase during heating/cooling processes are well recovered here by changing the po- 

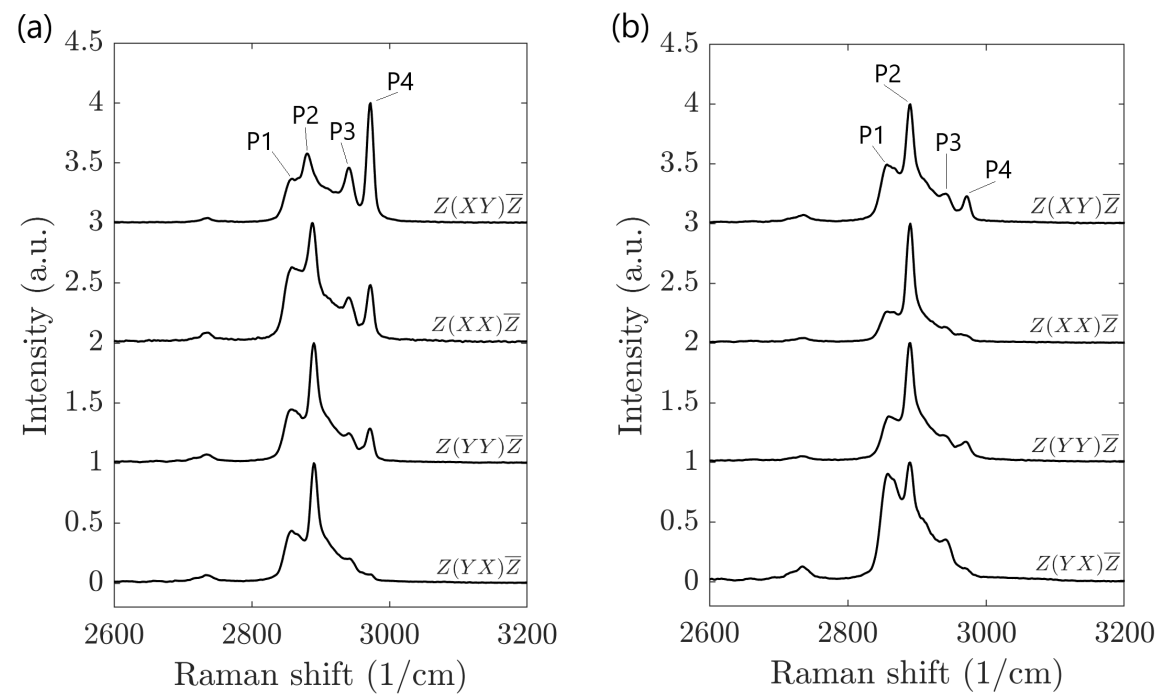

Figure 19: Polarized Raman spectra for the four geometries of polarization. Example for two different fixed positions of acquisition (a) and (b).

larization geometry. For this reason the variation of $P_{2} / P_{1}$ for solid phase in Fig. 16 is mainly caused by the different crystallites orientations. Moreover, the large variability in the PCA scores for the solid phase indicates spectra that differ statistically from one another. This variability can be related to structural changes in the sample, especially when the spectrum is acquired near the solidification point, but also to the differences observed for different orientations of crystallites. Formation of differently oriented crystallites could be explained by uncontrolled boundary conditions in terms of geometry or surfaces, where the roughness of the lateral surfaces of the sample reservoir here used is different from that of the bottom surface, or by any random heterogeneity. Finally, crystallization process and crystallites orientations depend on the surface tension since here the upper interface is a "free" surface in contact with air. Since this region is the last where crystallization occurs, it is also subjected to volume shrinkage that forms a heterogeneous, rough surface.

\section{Discussion and conclusive remarks}

In this work we provide a multi-physical and multi-scale characterization for hexadecane's liquid and solid phases as well as for the phase change during 
melting and solidification. Hexadecane's thermo-mechanical properties are indeed investigated at macroscopic and microscopic scale as a function of temperature by achieving the phase transition with different techniques and protocols, i.e. transient or quasi-static temperature variations. The attempt is justified given the importance that such type of organic PCMs has in many industrial processes and by the lack in their proper characterization.

First, we have presented results for hexadecane's thermo-physical properties at the macroscopic scale. The thermal conductivity $\lambda$ of both liquid and solid phases were retrieved for the first time by the hot tube technique and compared with the available literature. $\lambda$ in the liquid phase is found in good agreement with previous works (deviations within $6 \%$ with [15] and $\sim 18 \%$ with [44]). Similarly, our value of $\lambda$ in solid phase deviates by only $1.8 \%$ from the only other available measure [15]. The thermal conductivity of the solid phase is found larger than the one of the liquid phase, with a ratio between the two of $\sim 2.27$.

Afterwards, differential scanning calorimetry (DSC) was used to determine the latent heat for both melting and solidification processes and the specific thermal capacity for liquid and solid phases. The same technique allows also to achieve the temperatures at which hexadecane melts $\left(T_{m}\right)$ and starts to solidify $\left(T_{s}\right)$. Their values are listed in Table 1 together with those obtained with the other analysis techniques. Even when using DSC with a relative small temperature $\operatorname{ramp}\left(0.2^{\circ} \mathrm{C} / \mathrm{min}\right)$, we always recorded a thermal hysteresis of about $2{ }^{\circ} \mathrm{C}$ between the onset of the phase change during melting and that during solidification. A similar thermal hysteresis was also collected during rheological analysis where $T_{s}$ is found to depend on the chosen temperature ramp for both rotational and oscillatory tests. Processes involving fast temperature variations $\left(1.0{ }^{\circ} \mathrm{C} / \mathrm{min}\right)$ are indeed characterized by a $T_{s}$ that is considerably lower than what obtained for smaller cooling rate (up to $3{ }^{\circ} \mathrm{C}$ difference in oscillatory mode), leading to a even larger thermal hysteresis. On the other hand, small cooling rates decrease supercooling effects and lead to a smaller difference between $T_{s}$ and $T_{m}$ even compared to DSC. Near the solidification temperature, the forming solid structure is continuously affected also by the conditions imposed by the rheometer. This is shown in oscillatory tests done at steady temperature. At $T \leq 16.0^{\circ} \mathrm{C}$ hexadecane's transient behavior reaches a stage where the solid-like behavior dominates and, even though weakly, $G^{\prime}$ remains larger than $G^{\prime \prime}$. Under this condition, the measured normal force displays periodic discontinuities that can be related to the breakage/growth of crystals along the plate-sample interface 


\begin{tabular}{ccc}
\hline Technique & $\begin{array}{c}\text { Solidification } \\
\text { temperature }\left({ }^{\circ} \mathrm{C}\right)\end{array}$ & $\begin{array}{c}\text { Melting } \\
\text { temperature }\left({ }^{\circ} \mathrm{C}\right)\end{array}$ \\
\hline DSC & $T_{s}=15.0-15.5$ & $T_{m}=17.2-17.7$ \\
Oscillatory rheometer & $T_{G^{\prime}>G^{\prime \prime}} \leq 16.0$ & $T_{m} \sim 17.5$ \\
Raman & $T_{s}=17.3$ & $T_{m}=17.7$ \\
\hline
\end{tabular}

Table 1: Phase change temperatures regarding different techniques.

even for the smallest imposed stress $(0.001 \mathrm{~Pa})$. Rheological tests highlight two counteracting phenomena when applying a weak strain or stress to the PCM: (1) it facilitates phase transition by homogenizing the temperature due to advection, (2) it leads to a weakening of the crystallites structure during the liquid-to-solid transition. Forces exerted by the imposed shear stress can overcome the driving forces of crystallization and lead to the breakage of the forming structure.

Melting and solidification at microscale were studied through Raman spectroscopy. These measurements regard the "local" phase change since the laser beam is focused on a $\mu \mathrm{m}$-spot right below the sample top surface. Results show a local melting temperature $\left(T_{m}=17.7^{\circ} \mathrm{C}\right)$ close to what found by DSC and by rheology measurements (Table 1 ). This temperature deviates by only $2.2 \%$ from the values of $T_{m}$ found by [40] for a much smaller sample of hexadecane. On the other hand, both the temperature evolution of the ratio between Raman's peaks associated to the $\mathrm{CH}_{2}$ stretching $\left(P_{2} / P_{1}\right)$ and the PCA score plots show that, by waiting long enough, crystallization starts at $T=17.3^{\circ} \mathrm{C}$, thus considerably reducing the thermal hysteresis to about $0.4^{\circ} \mathrm{C}$. It has been shown that an uniformly cooled liquid $n$-alkanes can undergo surface freezing by forming a crystalline monolayer on its surface at $3{ }^{\circ} \mathrm{C}$ above the bulk $T_{s}[58,59]$. Although in our case boundary conditions for the temperature are different from those of $[58,59]$, this phenomenon could take place along the liquid-air interface of our sample and contribute to the mismatch between the local $T_{s}$ obtained by Raman spectroscopy and the bulk $T_{s}$ obtained for small temperature ramps with DSC. Furthermore, a large value of roughness can contribute to favor the occurrence of freezing, as in the case for the cavity surfaces used to contain the PCM during our Raman analysis. In our case, while solidification was measured locally by Raman spectroscopy, a solidification within the whole volume was observed. Variations in boundary conditions, such as thermal conditions and/or 
kinematical, dynamical conditions can significantly affect the way hexadecane's solidification occurs. In addition, mechanical or even some physicochemical conditions can favor crystallization by inducing nucleation. This has in turn a strong impact on how much efficiently energy is generated and absorbed during the phase change and it needs to be taken carefully into account when designing new thermal energy storage systems. For these reasons, PCM interactions at interfaces are of utmost importance because they can modify the sample bulk properties as well as equilibrium states.

Our ongoing work is currently dedicated to reduce PCMs supercooling. One interesting route to address this issue is to provide nucleation sites to favor crystallization, e.g. by using porous materials which increase the available solid surface to create sites for nucleation. In this case a complete investigation on structural properties and phase transition mechanisms of PCMs inside porous network will be mandatory to evaluate the ability of the system to trigger crystals nucleation. 


\section{Acknowledgments}

Financial supports have been brought to this work by the operation "STOCK'NRJ" co-financed by the European Union within the framework of the Program FEDER-FSE Lorraine and Massif des Vosges 2014-2020.

\section{References}

[1] K. Pielichowska, K. Pielichowski, Phase change materials for thermal energy storage, Progress in Materials Science 65 (2014) 67-123.

[2] S. Zhang, D. Feng, L. Shi, L. Wang, Y. Jin, L. Tian, Z. Li, G. Wang, L. Zhao, Y. Yan, A review of phase change heat transfer in shapestabilized phase change materials (ss-PCMs) based on porous supports for thermal energy storage, Renewable and Sustainable Energy Reviews 135 (2021) 110127.

[3] A. Sharma, V. V. Tyagi, C. Chen, D. Buddhi, Review on thermal energy storage with phase change materials and applications, Renewable and Sustainable Energy Reviews 13 (2) (2009) 318-345.

[4] F. Agyenim, N. Hewitt, P. Eames, M. Smyth, A review of materials, heat transfer and phase change problem formulation for latent heat thermal energy storage systems (LHTESS), Renewable and Sustainable Energy Reviews 14 (2) (2010) 615-628.

[5] H. Akeiber, P. Nejat, M. Z. A. Majid, M. A. Wahid, F. Jomehzadeh, I. Z. Famileh, J. K. Calautit, B. R. Hughes, S. A. Zaki, A review on phase change material (PCM) for sustainable passive cooling in building envelopes, Renewable and Sustainable Energy Reviews 60 (2016) 14701497.

[6] G. Ferrer, A. Solé, C. Barreneche, I. Martorell, L. F. Cabeza, Review on the methodology used in thermal stability characterization of phase change materials, Renewable and Sustainable Energy Reviews 50 (2015) 665-685. 
[7] B. R. Hughes, M. Cheuk-Ming, A study of wind and buoyancy driven flows through commercial wind towers, Energy and Buildings 43 (7) (2011) 1784-1791.

[8] Y. Zhao, X. Zhang, X. Xu, S. Zhang, Research progress of phase change cold storage materials used in cold chain transportation and their different cold storage packaging structures, Journal of Molecular Liquids (2020) 114360.

[9] E. Oró, A. De Gracia, A. Castell, M. M. Farid, L. F. Cabeza, Review on phase change materials (PCMs) for cold thermal energy storage applications, Applied Energy 99 (2012) 513-533.

[10] N. S. Dhaidan, J. Khodadadi, Melting and convection of phase change materials in different shape containers: A review, Renewable and Sustainable Energy Reviews 43 (2015) 449-477.

[11] S. Mondal, Phase change materials for smart textiles-An overview, Applied Thermal Engineering 28 (11-12) (2008) 1536-1550.

[12] D. C. Spencer, R. F. Katz, I. Hewitt, Magmatic intrusions control Io's crustal thickness, Journal of Geophysical Research: Planets 125 (6) (2020) e2020JE006443.

[13] B. Zalba, J. M. Marm, L. F. Cabeza, H. Mehling, Review on thermal energy storage with phase change: materials, heat transfer analysis and applications, Applied Thermal Engineering 23 (3) (2003) 251-283.

[14] D. Zhou, C.-Y. Zhao, Y. Tian, Review on thermal energy storage with phase change materials (PCMs) in building applications, Applied Energy 92 (2012) 593-605.

[15] C. Vélez, M. Khayet, J. O. De Zárate, Temperature-dependent thermal properties of solid/liquid phase change even-numbered n-alkanes: nhexadecane, n-octadecane and n-eicosane, Applied Energy 143 (2015) 383-394.

[16] H. Inaba, M.-J. Kim, A. Horibe, Melting heat transfer characteristics of microencapsulated phase change material slurries with plural microcapsules having different diameters, Journal Heat Transfer 126 (4) (2004) $558-565$. 
[17] A. Sarı, C. Alkan, C. Bilgin, Micro/nano encapsulation of some paraffin eutectic mixtures with poly (methyl methacrylate) shell: Preparation, characterization and latent heat thermal energy storage properties, Applied Energy 136 (2014) 217-227.

[18] R. Velraj, R. Seeniraj, B. Hafner, C. Faber, K. Schwarzer, Heat transfer enhancement in a latent heat storage system, Solar Energy 65 (3) (1999) $171-180$.

[19] X. Huang, C. Zhu, Y. Lin, G. Fang, Thermal properties and applications of microencapsulated PCM for thermal energy storage: A review, Applied Thermal Engineering 147 (2019) 841-855.

[20] J. Noel, C. Métivier, S. Becker, S. Leclerc, Natural convection in phase change material: Experimental study, International Journal of Heat and Mass Transfer 183 (2022) 122047.

[21] Z. Chen, D. Gao, J. Shi, Experimental and numerical study on melting of phase change materials in metal foams at pore scale, International Journal of Heat and Mass Transfer 72 (2014) 646-655.

[22] H. M. Ali, M. M. Janjua, U. Sajjad, W.-M. Yan, et al., A critical review on heat transfer augmentation of phase change materials embedded with porous materials/foams, International Journal of Heat and Mass Transfer 135 (2019) 649-673.

[23] Z. Wang, Z. Zhang, L. Jia, L. Yang, Paraffin and paraffin/aluminum foam composite phase change material heat storage experimental study based on thermal management of Li-ion battery, Applied Thermal Engineering 78 (2015) 428-436.

[24] L. F. Cabeza, C. Barreneche, I. Martorell, L. Miró, S. Sari-Bey, M. Fois, H. O. Paksoy, N. Sahan, R. Weber, M. Constantinescu, et al., Unconventional experimental technologies available for phase change materials (PCM) characterization. Part 1. Thermophysical properties, Renewable and Sustainable Energy Reviews 43 (2015) 1399-1414.

[25] M. Faden, S. Höhlein, J. Wanner, A. König-Haagen, D. Brüggemann, Review of thermophysical property data of Octadecane for phase-change studies, Materials 12 (18) (2019) 2974. 
[26] W. E. O'Connor, R. Warzoha, R. Weigand, A. S. Fleischer, A. P. Wemhoff, Thermal property prediction and measurement of organic phase change materials in the liquid phase near the melting point, Applied Energy 132 (2014) 496-506.

[27] C. Arkar, S. Medved, Influence of accuracy of thermal property data of a phase change material on the result of a numerical model of a packed bed latent heat storage with spheres, Thermochimica Acta 438 (1-2) (2005) 192-201.

[28] A. Sarı, A. Karaipekli, Thermal conductivity and latent heat thermal energy storage characteristics of paraffin/expanded graphite composite as phase change material, Applied Thermal Engineering 27 (8-9) (2007) $1271-1277$.

[29] S. Kalaiselvam, M. Veerappan, A. A. Aaron, S. Iniyan, Experimental and analytical investigation of solidification and melting characteristics of PCMs inside cylindrical encapsulation, International Journal of Thermal Sciences 47 (7) (2008) 858-874.

[30] G. Fang, H. Li, Z. Chen, X. Liu, Preparation and characterization of flame retardant n-hexadecane/silicon dioxide composites as thermal energy storage materials, Journal of Hazardous Materials 181 (1-3) (2010) 1004-1009.

[31] C. Moulahi, A. Trigui, M. Karkri, C. Boudaya, Thermal performance of latent heat storage: Phase change material melting in horizontal tube applied to lightweight building envelopes, Composite Structures 149 (2016) 69-78.

[32] I. Chriaa, A. Trigui, M. Karkri, I. Jedidi, M. Abdelmouleh, C. Boudaya, Thermal properties of shape-stabilized phase change materials based on Low Density Polyethylene, Hexadecane and SEBS for thermal energy storage, Applied Thermal Engineering 171 (2020) 115072.

[33] A. Safari, R. Saidur, F. Sulaiman, Y. Xu, J. Dong, A review on supercooling of Phase Change Materials in thermal energy storage systems, Renewable and Sustainable Energy Reviews 70 (2017) 905-919. 
[34] X. Liu, K. Zhuang, S. Lin, Z. Zhang, X. Li, Determination of supercooling degree, nucleation and growth rates, and particle size for ice slurry crystallization in vacuum, Crystals 7 (5) (2017) 128.

[35] M. Delgado, S. Gschwander, A. Lázaro, C. Peñalosa, B. Zalba, Determining the rheological behavior of octadecane as phase change material: First approach, Thermochimica Acta 548 (2012) 81-87.

[36] T. Tipvarakarnkoon, R. Blochwitz, B. Senge, Rheological properties and phase change behaviors of coconut fats and oils, Annual Transactions of the Nordic Rheology Society 16 (2008) 159-166.

[37] M. Delgado, A. Lázaro, M. Biedenbach, S. Gamisch, S. Gschwander, S. Höhlein, A. König-Haagen, D. Brüggemann, Intercomparative tests on viscosity measurements of phase change materials, Thermochimica Acta 668 (2018) 159-168.

[38] A. Louanate, R. El Otmani, K. Kandoussi, M. hamed Boutaous, Characterization of the rheological behavior of a paraffin-based phase change material under steady and oscillatory shear, Thermochimica Acta 704 (2021) 179018.

[39] M. Marchetti, M. Fois, L. Ibos, J. Dumoulin, P. Bourson, J.-M. Piau, Comparative study in the identification of liquid to solid transition phase with dsc, raman spectra analysis and chemiometrics methods applied to phase change materials used for icing-delay in civil engineering infrastructures, Applied Thermal Engineering 130 (2018) 49-61.

[40] S. Corsetti, T. Rabl, D. McGloin, J. Kiefer, Intermediate phases during solid to liquid transitions in long-chain n-alkanes, Physical Chemistry Chemical Physics 19 (21) (2017) 13941-13950.

[41] S. Outcalt, A. Laesecke, T. J. Fortin, Density and speed of sound measurements of hexadecane, The Journal of Chemical Thermodynamics 42 (6) (2010) 700-706.

[42] M. A. Matthews, J. B. Rodden, A. Akgerman, High-temperature diffusion, viscosity, and density measurements in n-hexadecane, Journal of Chemical and Engineering Data 32 (3) (1987) 317-319. 
[43] Y. Jannot, A. Degiovanni, Thermal properties measurement of materials, John Wiley \& Sons, 2018.

[44] R. Holmen, M. Lamvik, O. Melhus, Measurements of the thermal conductivities of solid and liquid unbranched alkanes in the $\mathrm{C}_{16}$-to- $\mathrm{C}_{19}$ range during phase transition, International Journal of Thermophysics 23 (1) (2002) 27-39.

[45] S. Himran, A. Suwono, G. A. Mansoori, Characterization of alkanes and paraffin waxes for application as phase change energy storage medium, Energy Sources 16 (1) (1994) 117-128.

[46] J. A. González, M. Zawadzki, U. Domanska, Thermodynamics of mixtures containing polycyclic aromatic hydrocarbons, Journal of Molecular Liquids 143 (2-3) (2008) 134-140.

[47] P. Zhang, Z. Ma, R. Wang, An overview of phase change material slurries: MPCS and CHS, Renewable and Sustainable Energy Reviews 14 (2) (2010) 598-614.

[48] G. S. Parks, G. E. Moore, M. L. Renquist, B. F. Naylor, L. A. McClaine, P. S. Fujii, J. A. Hatton, Thermal data on organic compounds. xxv. some heat capacity, entropy and free energy data for nine hydrocarbons of high molecular weight, Journal of The American Chemical Society 71 (10) (1949) 3386-3389.

[49] D. Richard, T. Speck, The role of shear in crystallization kinetics: From suppression to enhancement, Scientific Reports 5 (1) (2015) 1-7.

[50] M. Zheng, W. Du, Phase behavior, conformations, thermodynamic properties, and molecular motion of multicomponent paraffin waxes: A Raman spectroscopy study, Vibrational Spectroscopy 40 (2) (2006) 219224 .

[51] G. Socrates, Infrared and Raman characteristic group frequencies: tables and charts, John Wiley \& Sons, 2004.

[52] I. Duričković, R. Claverie, P. Bourson, M. Marchetti, J.-M. Chassot, M. D. Fontana, Water-ice phase transition probed by Raman spectroscopy, Journal of Raman Spectroscopy 42 (6) (2011) 1408-1412. 
[53] I. Duričković, M. Marchetti, R. Claverie, P. Bourson, J.-M. Chassot, M. D. Fontana, Experimental study of $\mathrm{NaCl}$ aqueous solutions by $\mathrm{Ra}-$ man spectroscopy: Towards a new optical sensor, Applied Spectroscopy 64 (8) (2010) 853-857.

[54] I. Duričković, L. Thiébaud, P. Bourson, T. Kauffmann, M. Marchetti, Spectroscopic characterization of urea aqueous solutions: Experimental phase diagram of the urea-water binary system, Applied Spectroscopy 67 (10) (2013) 1205-1209.

[55] L. A. Haskin, A. Wang, K. M. Rockow, B. L. Jolliff, R. L. Korotev, K. M. Viskupic, Raman spectroscopy for mineral identification and quantification for in situ planetary surface analysis: A point count method, Journal of Geophysical Research: Planets 102 (E8) (1997) 19293-19306.

[56] P. Colomban, Raman spectrometry, a unique tool to analyze and classify ancient ceramics and glasses, Applied Physics A 79 (2) (2004) 167-170.

[57] P. Espeau, L. Robles, D. Mondieig, Y. Haget, M. Cuevas-Diarte, H. Oonk, Mise au point sur le comportement énergétique et cristallographique des n-alcanes-i. Série de $\mathrm{C}_{8} \mathrm{H}_{18}$ à $\mathrm{C}_{21} \mathrm{H}_{44}$, Journal de Chimie Physique 93 (1996) 1217-1238.

[58] X. Wu, E. Sirota, S. Sinha, B. Ocko, M. Deutsch, Surface crystallization of liquid normal-alkanes, Physical Review Letters 70 (7) (1993) 958.

[59] B. Ocko, X. Wu, E. Sirota, S. Sinha, O. Gang, M. Deutsch, Surface freezing in chain molecules: Normal alkanes, Physical Review E 55 (3) (1997) 3164. 